\title{
NUEVOS DATOS SOBRE LAS OBRAS VASCAS DE PIERRE D'URTE
}

\author{
Josu M. Zulaika HeRnándeZ \\ Eusko Ikaskuntza - Sociedad de Estudios Vascos \\ zulaika@telefonica.net
}

\begin{abstract}
Resumen
El descubrimiento de correspondencia inédita entre G. W. Leibniz y J. Chamberlayne nos permitirá demostrar que fue éste quien encargó a P. d'Urte la redacción de la que habría de ser la primera gramática vasca de cierta extensión. Estas cartas pondrán de manifiesto, asimismo, la decisiva y hasta ahora desconocida influencia de Leibniz en la elaboración de los otros dos trabajos de Urte: su traducción parcial de la Biblia y su inacabado diccionario latín-vasco. Con respecto a esta última obra, creemos que la fuente de Urte fue el diccionario Linguae Romanae Dictionarium luculentum novum (1693). Por otro lado, una misiva remitida en 1716 por P. E. Jablonski a M. Veyssière de Lacroze, esboza la posibilidad de que por aquel entonces llegase a plantearse seriamente la publicación de la gramática de Urte. Finalmente, aportaremos datos que permitirán, pensamos que por vez primera, datar con bastante precisión la elaboración de la gramática vasca de N. Fréret, contemporánea a la de Urte.
\end{abstract}

PALABRAS CLAVE: Urte, Chamberlayne, Leibniz, lengua vasca.

\begin{abstract}
The finding and thorough study of some unpublished correspondence between G. W. Leibniz and J. Chamberlayne will enable us to demonstrate that it was the latter who entrusted P. d'Urte the writing of what would eventually become the first Basque grammar of a significant length. Likewise, said letters will show us the critical yet so far unknown influence exerted by Leibniz on Urte's two other works: his partial translation of the Bible and his incomplete Latin-Basque dictionary. Regarding the latter, we believe that Urte's source was the Linguae Romanae Dictionarium luculentum novum dictionary (1693). On the other hand, a letter sent by P. E. Jablonski to M. Veyssière de Lacroze in 1716 appears to indicate that publishing Urte's grammar was seriously considered by that time. In addition, we provide some data that allow us to accurately date the making of the Basque grammar by N. Fréret.
\end{abstract}

KEY WORDS: Urte, Chamberlayne, Leibniz, Basque Language.

\section{Introducción}

En el presente trabajo pretendemos aportar algunos datos que creemos novedosos sobre la figura y la obra del autor vasco-francés Pierre d'Urte, exiliado en Gran Bretaña desde finales del s. XVII por mor de su conversión al protestantismo en plena vigencia de la más absoluta intolerancia religiosa.

En primera instancia, trataremos de esbozar, de manera somera, la vida de Urte en Inglaterra y las circunstancias en que debieron de conocerse él y su mecenas británico, el lingüista John Chamberlayne. Abordaremos también, a renglón seguido, una sucinta descripción de 
las tres obras manuscritas que nos legó Urte: su gramática vasca, la traducción parcial de la Biblia y su inconcluso diccionario latín-vasco. Nos detendremos algo más en el estudio de esta última obra, pues creemos estar en disposición de afirmar que habría sido el Linguae Romanae Dictionarium luculentum novum de 1693 el modelo del que se habría servido Urte para su Dictionarium Latino-Cantabricum.

Posteriormente, transcribiremos los fragmentos relativos a la lengua vasca o euskara de las misivas que integran la relación epistolar entre Chamberlayne y el eminente filósofo, matemático y lingüista, Gottfried Wilhem Leibniz. Aunque parte de esta correspondencia ya fuera publicada en el s. XVIII, otras cartas permanecían, hasta su aparición en este artículo, inéditas. Es precisamente el contenido de estas misivas el que nos permitirá demostrar -más allá de anteriores intuiciones o presunciones- que en el año 1714 Urte estaba trabajando en la elaboración de su gramática vasca y que lo estaba haciendo por encargo de Chamberlayne. Veremos, además, cómo Chamberlayne le ofrece al filósofo germano la posibilidad de que Urte elaborase también un diccionario vasco. Leibniz, vívamente interesado -al menos desde el año 1691- en la obtención de una gramática y, sobre todo, un diccionario de la lengua vasca, aplaude la iniciativa de Chamberlayne, sugiriéndole, al mismo tiempo, la conveniencia de la traducción al euskara del Antiguo Testamento.

En tercer lugar, afrontaremos concisamente el estudio de la obra publicada en 1715 por Chamberlayne con el título de Oratio Dominica in diversas omnium fere gentium linguas versa, en tanto en cuanto entre los padrenuestros recogidos en dicha obra hay tres versiones en lengua vasca, la tercera de las cuales es atribuible a Urte. En la Oratio Dominica de 1715 aparecen, además, diversas colaboraciones de algunos de los lingüistas más prestigiosos del momento. Cuatro de estos autores (Leibniz, William Nicolson, William Wotton y Mathurin Veyssière de Lacroze) hacen referencia en sus ensayos al euskara, y aunque sus opiniones al respecto no sean -al menos en alguno de los casos- especialmente trascendentes, haremos alusión a las mismas, pues ponen de relieve la curiosidad que por aquellas fechas despertaba el vasco entre los eruditos ocupados en el estudio de las lenguas.

Finalmente, hablaremos de una carta remitida por Paul Ernst Jablonski a Lacroze en 1716. Aunque publicada en 1742, la misiva no parece haber sido tomada en consideración por los vascólogos. Nosotros, sin embargo, creemos que podría tener cierta relevancia pues en la misma se hace mención a la posible publicación de una gramática vasca. Si bien por aquellas fechas también Nicolas Fréret había escrito su Essay d'une Grammaire de la Langue Basque, expondremos las razones por las que consideramos que Jablonski sólo puede estar refiriéndose a la Grammaire Cantabrique de Urte.

\section{El exilio de Urte y su relación con Chamberlayne}

\subsection{Pierre d'Urte}

El hecho de que Pierre d'Urte no llegara a publicar en vida ninguna de sus obras, unido a la circunstancia de que los manuscritos de las mismas acabasen en la biblioteca privada $-\mathrm{y}$, por ello, de difícil acceso- del conde de Macclesfield ${ }^{1}$, motivaría que tanto la figura como la obra del au-

1 La espléndida biblioteca de los sucesivos condes de Macclesfield se ubica en Shirburn Castle, Watlington, en las cercanías de Oxford. Tal vez sería más correcto decir que se ubicaba allí, ya que el actual conde se ha visto 
tor labortano quedaran relegadas durante muchas décadas al olvido. Habría que esperar hasta el año 1884 para que, en su búsqueda de manuscritos célticos, John Rhys redescubriese casualmente las obras de Urte y pusiese en conocimiento del eminente vascólogo Louis Lucien Bonaparte su hallazgo ${ }^{2}$. Sólo a partir de aquella fecha tendrían inicio las exhaustivas indagaciones en los más diversos registros públicos y privados en busca de referencias acerca de la vida de un hasta entonces desconocido Urte y, lo que es más importante, comenzarían a editarse sus obras.

Por los escasos datos que hasta ahora se han podido extraer de tales registros, sabemos que Urte nació en Donibane Lohizune (Saint-Jean-de-Luz) el 1 de enero de $1664^{3}$. Originariamente fue un religioso católico ${ }^{4}$, muy probablemente franciscano, que convertido al protestantismo se vio obligado a exiliarse -en su caso a Inglaterra- a causa de la revocación del Edicto de Nantes. No se ha podido averiguar la fecha de su partida de Francia, pero hay documentos que lo sitúan ya en Londres en el año 1699 con motivo de su matrimonio con la también refugiada, Judith Gautereau ${ }^{5}$. Hay, asimismo, datos relativos a la estancia de Urte en la capital británica en los años 1706, 1716, 1717 y 1719, fecha esta última en la que, tras enviudar, vuelve a casarse. Cabe suponer que Urte debió de permanecer en Londres hasta su fallecimiento, del cual desconocemos la fecha ${ }^{6}$.

\subsection{La relación entre Urte y Chamberlayne}

El lingüista británico John Chamberlayne ${ }^{7}$ era miembro, desde su fundación en 1698, de la anglicana Society for the Propagation of Christian Knowledge ${ }^{8}$. Dicha sociedad tomó parte

obligado por decisión judicial a abandonar su mansión y, por razones de espacio, ha puesto a la venta su impresionante colección de libros. Por otro lado, y en cuanto a las vicisitudes que pudieron correr los manuscritos de Urte antes de llegar a dicha biblioteca, debemos descartar la posibilidad-simplemente apuntada por Thomas (1894: viii), pero seguida después por la práctica totalidad de la crítica- de que éstos hubiesen estado en posesión de Edward Lhuyd. Tal circunstancia es imposible, pues el autor galés falleció en 1709, antes de que Urte comenzase a escribir sus obras. La fuente de Thomas en este punto fue John Rhys (1885: 86), quien, a su vez, se había hecho eco de las notas aparecidas en el catálogo que Edward Edwards (1864: 352) realizara de la biblioteca de Shirburn Castle.

2 Tanto Rhys como Bonaparte publicaron sendas notas al respecto -la de este último no demasiado afortunadaen la revista The Academy de 13-09-1884 y 8-11-1884, respectivamente. Las consideraciones de ambos autores fueron editadas pocos meses después -traducidas al español- en la revista Euskal-Erria, lo que falicitó la difusión del descubrimiento de Rhys entre los vascólogos de la época.

3 Urkizu, 1989: I, 29.

4 Ello parece seguro, a pesar de la paradójica afirmación del propio Urte (Urkizu, 1989: I, 31) en su Grammaire Cantabrique: «dès le ventre de ma mère je suis né très insensible pour toutes les superstitions de l'Eglise romaine». En los registros se le cita como «pretre converti» o como «capucin», y Chamberlayne le define como un «Poor Biscayan Priest (now a Protestant)» en carta remitida a Leibniz con fecha 18-02-1714 (vid. inf. § 3.3).

5 Urkizu, 1989: I, 48.

6 Ignoramos cuáles son las fuentes que permiten a Etxegoien (2006: 118) escribir que Urte emigró a Norteamérica en 1717 y que murió allí: «1717an Ipar Ameriketara zen joan eta bertan hil». Recordemos que en 1719 los registros le sitúan contrayendo matrimonio en Londres.

7 John Chamberlayne (Londres ca.1666 - Londres 1723) fue hijo de Edward Chamberlayne, autor conocido sobre todo por su obra Angliae Notitia, cuya primera edición dataría de los años 1669-1671. A partir de la muerte de su padre en 1703, John Chamberlayne se haría cargo de las posteriores reediciones de la obra (desde 1708 ya con el nuevo título de Magnae Britanniae Notitia). Amén de sus aficiones literarias, Chamberlayne fue un cortesano que estuvo en primera instancia al servicio del príncipe Jorge de Dinamarca, y más tarde de la reina Ana de Inglaterra y de su sucesor, Jorge I. 8 "He was appointed Secretary to the S.P.C.K. shortly after his foundation, and held this post until March 5, 1701, when he resigned, owing to the many different bussines which lye heavy upon him. He still continued, however, to 
de manera muy activa en la ayuda espiritual y económica para con la multitud de refugiados que, como Urte, hubieron de abandonar Francia con motivo de sus creencias religiosas. De hecho, muchos miembros de la S.P.C.K., entre ellos Chamberlayne, formaban parte de la lista de comisionados que en 1717 el rey Jorge I nombró para supervisar personalmente las ayudas económicas a los exiliados franceses.

No cabe duda de que fue la especial implicación de Chamberlayne para con los refugiados menesterosos, la que propició su relación con Urte ${ }^{9}$. Chamberlayne, interesado como estaba en todo lo relacionado con el estudio de las lenguas, tanto clásicas como modernas ${ }^{10}$, halló en el religioso labortano a un vasco instruido perfectamente capacitado para tratar de aportar algo de luz sobre la misteriosa y desconocida lengua vasca. Comoquiera que, por otro lado, las ayudas que recibían los refugiados eran de muy escasa cuantía ${ }^{11}$, parece lógico pensar que Urte aceptaría con agrado la proposición de su nuevo mecenas de escribir una gramática de la lengua vasca -ésta fue la primera petición de Chamberlayne- a cambio de una compensación económica que pudiese aliviar en algo su precaria situación.

\subsection{Las obras vascas de Urte}

\subsubsection{Grammaire Cantabrique [ca.1714]}

De las tres obras que nos legó Urte, la gramática vasca es la que primero empezó a escribir y la única que finalizó ${ }^{12}$. Se trata de la primera gramática de cierta extensión de la lengua

help the Society in many ways" (Allen, 1898: 18). De igual modo, Chamberlayne (1718: II, 148, 152) fue, desde su institución en 1701, miembro y primer secretario de la Society for the Propagation of the Gospel in Foreign Parts y detentó el cargo de secretario del Bounty of Queen Anne for the Augmentation of the Maintenance of the Poor Clergy.

9 Ya dijo Vinson (1897: 225) al respecto: «nous savons aussi que Chamberlayne était un des commisaires, ce qui explique que d'Urte ait été en rapports avec lui: il donne le nom de Chamberlayne, dans sa grammaire, comme exemple de noms de famille».

10 A los 19 años de edad, Chamberlayne inició sus estudios superiores en el prestigioso Trinity College de Oxford. Poco tiempo después, en 1688, se trasladaría a Leiden, en cuya universidad estudiaría lenguas vivas. En los registros biográficos de la Royal Society -institución de la cual fue miembro desde el año 1702- se dice que Chamberlayne conocía 16 idiomas. Aunque el dato tal vez sea un tanto exagerado, sí tenemos constancia de que -además del inglés- dominaba el griego, latín, francés, alemán, flamenco, portugués e italiano. Es precisamente su condición de políglota la que marca el sentido de su producción literaria, ya que la práctica totalidad de sus libros no son sino traducciones al inglés de obras de la más variada índole.

11 Urte, como el resto de refugiados protestantes en Inglaterra, recibía una modesta ayuda económica. Así, Vinson y Clark (1893b: 312) nos hablan de la asignación de 15 libras en el año 1706: «Pierre d’Urte, de SaintJean-de-Luz, prêtre converti, assisté à Londres (15 1.) avec sa femme et son enfant, 1706». La prestación había sido reducida a 6 libras en 1717, según nos refiere nuevamente Vinson (1897: 228): «Meeting, June, 21, 1717: Peter D'Urte of Bearne in France, formerly a Capuchin, being in years, and having a wife, and one child, the Com. one of opinion that he be allowed six pounds». Tras enviudar en 1717, volvió a casarse dos años después en Londres con Magdalen L'Hermett, boda que se llevó a cabo sin el consentimiento de los comisarios, por lo que le fue retirada todo tipo de ayuda económica: "Meeting, October, 10, 1719: That Peter D'Urte is married without the consent of the Com, for which he was excluded in the last distribution, since which he is gone off with his daugther by a former Wife, and his present Wife being no Proselyte is not an object of the charity of the Commissioners" (Vinson 1897: 228).

12 Sobre la controvertida cuestión de si realmente podemos considerar la gramática de Urte como una obra acabada o no, vid. inf. § 5.3 . 
vasca. El manuscrito original, que consta de 540 páginas encuadernadas en un solo volumen, fue adquirido en octubre de 2008 -junto con el Dictionarium Latino-Cantabricum- por la Fundación Sancho el Sabio de Vitoria-Gasteiz ${ }^{13}$.

Wentworth Webster publicaría por partes la gramática de Urte en el Bulletin de la Société Ramond entre 1896 y 1900, y ya de manera completa -en forma de separata- en 1900. No obstante, Vinson y Clark ya habían editado entre 1893 y 1894 parte de esta obra, concretamente sus dos vocabularios.

La que en alguna ocasión Urte (Webster, 1900: 517) denomina Escaldun Gramarioa, es una gramática de la lengua vasca escrita en francés, en la cual el estudio del verbo ocupa un lugar preponderante. Oyharçabal (1989: 69) puso en su día de relieve su carácter de gramática pedagógica, pero sin poder descubrir la fuente de la que se había servido Urte para elaborar su obra. Ha sido Gidor Bilbao (2008) quien recientemente ha podido demostrar que Urte tomó como modelo la Grammaire Francoise de Claude Mauger ${ }^{14}$, gramática bilingüe cuya finalidad era la enseñanza a los británicos del idioma francés.

\subsubsection{Biblia Saindua [ca.1715]}

El proyecto de Urte de traducir al euskara la Biblia se truncó -ignoramos las razonesabruptamente y, finalmente, su trabajo tan solo contiene el Génesis (Ethorquia) y los 22 primeros capítulos del Éxodo (Ilkhitçea). El manuscrito, que consta de 131 folios escritos a doble cara y encuadernados en un volumen, se ubica actualmente en una biblioteca privada bilbaína ${ }^{15}$.

Sería Llewelyn Thomas el primero en publicar, en 1894, la traducción parcial del Antiguo Testamento $^{16}$. En cuanto a la fuente de Urte, el propio Thomas (1894: xvi) nos hizo saber que el religioso labortano habría realizado su traducción sirviéndose de la versión autorizada francesa de la Biblia de Ginebra.

13 Comentábamos anteriormente que el conde de Macclesfield se había visto en la necesidad de poner a la venta su biblioteca. Sotheby's, la prestigiosa casa de subastas, es la encargada de tal transacción y, dado el volumen de la biblioteca, los libros y manuscritos de la misma se están vendiendo de forma escalonada. Ha sido en una de estas subastas, y por el precio de 56.450 libras esterlinas, donde la Fundación Sancho el Sabio ha adquirido la gramática y el diccionario de Urte. La Fundación se hizo con estas obras de forma anónima, creándose por ello cierto revuelo en los ambientes culturales vascos ante el temor de que el comprador hubiese sido algún acaudalado coleccionista de libros y las obras del religioso labortano hubiesen ido a parar, de nuevo, a una biblioteca privada. Sólo en mayo de 2009 la Fundación desveló a los medios de comunicación su importante adquisición, haciendo coincidir esta noticia con la inauguración de su nueva sede en Vitoria.

14 Mauger editó por primera vez su obra en 1653 con el título de The True Advancement of the French Tongue, y debido a su éxito fueron muchísimas sus reediciones, casi siempre con variaciones tanto en el título como en el contenido. Gidor Bilbao realiza la comparación entre las gramáticas de Urte y Mauger basándose en la undécima edición (1684) de la obra de este último.

15 Un bibliófilo bilbaíno, José María Arriola, adquirió en el año 2006, en las referidas subastas de Sotheby’s, el Antiguo Testamento de Urte por la suma de 42.000 libras.

16 En realidad, y atendiendo al título con el que Urte encabezó su trabajo, parece que su intención inicial era la traducción de la totalidad de la Biblia, y no sólo del Antiguo Testamento: «Bibliá Saindua: Testament çahárra eta berriä iduquitçen dituena bertçéla Aliéntçia çaharra eta berriá edo Iscritura saindu guçia» (Thomas, 1894: 1). 


\subsubsection{Dictionarium Latino-Cantabricum [ca.1715]}

\subsubsection{El manuscrito y su edición}

El que Urte subtitulara Latignescarazco Diccionarióa es, como la traducción de la Biblia, una obra inacabada. El manuscrito ocupa 2457 folios encuadernados en cinco volúmenes, y ello teniendo en cuenta que abarca solamente desde $A, a b$, abs hasta la palabra Commotus. Con razón pudo decir Llewelyn Thomas (1894: xi) que «is a huge phrase-book rather than a Dictionary»».

Afortunadamente, erró Azkue (1928: 224) cuando predijo que el diccionario de Urte era «y creo será siempre obra inédita». Webster había publicado en 1895, a modo de muestra, un pequeño fragmento del mismo -sólo desde $A, a b$, abs hasta ablegare-, pero sería posteriormente Urkizu quien lo editase en su integridad, en 1989, con el título de Pierre d'Urteren Hiztegia, Londres 1715.

\subsubsection{La posible fuente de Urte: Linguae Romanae Dictionarium luculentum novum (1693)}

Ni Thomas ${ }^{17}$, al describir sumariamente el contenido de los manuscritos de Urte, ni Webs$\operatorname{ter}^{18}$ en su publicación parcial del Dictionarium, ni su editor definitivo, Urkizu ${ }^{19}$, consiguieron hallar la obra que en su día sirviese de referencia a Urte para la elaboración de su trabajo lexicográfico. La cuestión era compleja, porque no fueron pocos los diccionarios editados entre finales del s. XVII y principios del s. XVIII, sin que además se supiera si la búsqueda había que efectuarla entre los diccionarios franceses o entre los ingleses.

Hoy, merced al contenido de una carta hasta ahora inédita ${ }^{20}$, sabemos que habría sido Chamberlayne quien le proporcionase a Urte para su trabajo «a good Latin or French Dictionary». La afirmación de Chamberlayne, no obstante, es demasiado vaga como para poder servir de orientación alguna en la búsqueda.

Pese a todo, un poco por empeño y un mucho por azar, creemos haber conseguido descubrir el «Dictionary» que finalmente Chamberlayne habría entregado a Urte. Una vez examinados un buen número de diccionarios latinos editados en aquella época (tanto en Francia como en Inglaterra ${ }^{21}$ ), pensamos que el que más parecido guarda con el de Urte es el editado en Cambridge, en 1693, con el título de Linguae Romanae Dictionarium Luculentum Novum.

17 «It is probably founded upon some old Latin-French work, which we hope to discover» (Thomas, 1894: xi).

18 «Le Dictionnaire Latin dont P. d'Urte s'est servi pour ses traductions basques doit avoir été un des lexiques en usage de son temps dans les collèges et les Universités, surtout pour apprendre à parler et à écrire le latin. Nous n'avons pu en retrouver l'original. Ce n'était pas seulement un dictionnaire de la langue classique. Il se retrouve des mots de basse-latinité qu'on ne trouve que dans le Glossarium de Du Cange et dans d'autres lexiques du moyen âge» (Webster, 1895: 543).

19 «Baratxe ikertu ondoren hiztegia, eta berau aski berezia delarik, ausartuko ginateke esatera hiztegi bat baino gehiagotaz baliatu zela berea moldatzen hasterakoan, ez bakarrik Robert Estienne-renaz, baita ere, agian Londresen aurkituko zituen Davis-en bezalako beste latin-britannicum hiztegiez» (Urkizu, 1989: I, 94).

20 Vid. inf. $\$ 3.3$.

21 En cuanto a los diccionarios latino-ingleses, hemos revisado, entre otros -y por citar sólo aquellos que por su fecha y su estructura pudieran guardar algún paralelismo con el Dictionarium de Urte-, las obras de Christopher Wase (las ediciones de 1662 y 1675); Gouldman (1664 y 1674); Francis Thomas Holyoke (1677); Elisha Coles (1677, 1679, 1692, 1693, 1707 y 1711) y Adam Littleton (1678, 1684, 1703 y 1715). 
La obra en cuestión está dividida en cinco partes, la segunda de las cuales es un diccionario latino-inglés titulado «Linguae Latinae Dictionarium luculentum novum». Es, precisamente, esta parte de la obra la que habría sido la principal fuente del Dictionarium de Urte ${ }^{22}$.

A su vez, la base del diccionario anónimo de 1693 fue la obra de Adam Littleton (1627 1694), Linguae Latinae liber dictionarius quadripartitus, editada por vez primera en 1678. Littleton publicó una segunda edición de su diccionario en 1684 y, aunque algunos críticos también le consideren como autor de la edición de Cambridge de 1693, lo cierto es que ésta fue publicada ya en las postrimerías de su vida y sin contar con su aquiescencia. Además del diccionario de Littleton, los autores del Linguae Romanae Dictionarium también utilizaron, según hicieron constar en la propia portada de su obra, «the several Works of Stephens, Cooper, Gouldman, Holyoke, Dr. Littleton, [and] a large manuscript, in three volumes, of Mr. John Milton, \&c».

Confrontando las 40 primeras entradas latinas de las letras $A$ y $B$ del diccionario de Urte (Urkizu, 1989: II, 11-12, 339-340), con las correspondientes del Dictionarium de 1693, podemos apreciar que el paralelismo entre ambas obras es más que evidente:

\begin{tabular}{|l|l|}
\hline \multicolumn{1}{|c|}{ URTE $(c a .1715)$} & \multicolumn{1}{|c|}{ DICTIONARIUM (1693) } \\
\hline $\mathrm{A}, \mathrm{AB}, \mathrm{ABS}$ & A, ab, abs \\
\hline $\begin{array}{l}\text { ab oriente }[\ldots] \text { ab occidente }[\ldots] \text { ab aquilone }[\ldots] \\
\text { a meridie }\end{array}$ & Ab oriente, Ab occidente, Ab aquilone, A meridie \\
\hline venio ab urbe, ab agro, ab agris & Venio ab urbe $[\ldots]$ ab agro \\
\hline redeo a villa & Redeo à villa \\
\hline Aeneas fugiens a Troja & Aeneas fugiens à Troja \\
\hline a Tenedo & A Tenedo \\
\hline Romá profugerunt & Româ profugerunt \\
\hline Capua Romam petit & Capuâ Romam petit \\
\hline domo, rure, humo & Domo, Rure, \& humo \\
\hline video rure redeuntem senem & Video rure redeuntem senem \\
\hline domo dudum huc accersita sum & Domo dudum huc accersita sum \\
\hline & $\grave{a}$ Theatro venit \\
\hline a prope & \\
\hline venio a propé & \\
\hline a procul, ab hinc, ab illinc & \\
\hline ab intro, ab extra & \\
\hline a sursum, a deorsum & \\
\hline usque a capitolio & usque à Capitolio \\
\hline & usque ab aurora \\
\hline a principio & A principio \\
\hline ab illo tempore & ab illo tempore \\
\hline usque ab aurora & \\
\hline
\end{tabular}

22 Urte también habría hecho uso, para los nombres propios, de la parte tercera de la obra: el «Dictionarium Propria Locorum \& Personarum vocabula complectens». Tal sería el caso de nombres como Aarasus, Aaron y un largo etcétera. 


\begin{tabular}{|l|l|}
\hline \multicolumn{1}{|c|}{ URTE $(c a$. 1715) } & \multicolumn{1}{c|}{ DICTIONARIUM (1693) } \\
\hline a prima luce & A primâ luce \\
\hline & ab Aurorâ \\
\hline a coena & A coena \\
\hline a Jentaculo & A jentaculo \\
\hline a media nocte & A media nocte \\
\hline ab incunabulis & Ab incunabulis \\
\hline ab infantia & Ab infantiâ \\
\hline a puero, a parvulo, ab pueritia & A parvulo, à puero, ab pueritiâ \\
\hline ab ineunte adolescentia & Ab ineunte adolescentiâ \\
\hline ab hoc sermone & Ab hoc sermone \\
\hline a primo & $\grave{a}$ primo \\
\hline utinam a primo ita tibi esset visum & Utinam à primo ita tibi esset visum \\
\hline a limine disciplinas salutare & A limine disciplinas salutare \\
\hline ab ostio auscultavi & Ab ostio auscultavi \\
\hline a via salutare & A viâ salutare \\
\hline bacillum leviter a summo inflexum & Bacillum leviter à summo inflexum \\
\hline Cadus a summo plenus & Cadus à summo plenus \\
\hline ab extremo ordiri & ab extremo ordiri \\
\hline funiculus a puppi, religatus & Funiculus à puppi religatus \\
\hline a rege secundus & A Rege secundus \\
\hline dulcissimum ab hominis camelinum lac & Dulcissimum ab hominis Camelinum lac \\
\hline
\end{tabular}

\begin{tabular}{|c|c|}
\hline URTE (ca. 1715) & DICTIONARIUM (1693) \\
\hline Babae & Babae \\
\hline babylonica vestis & Babylonǐca vestis \\
\hline babylonica & Babylonica \\
\hline babylonius & Babylonius, ii \\
\hline bacar & Bacar \\
\hline bacca & Bacca, ae \\
\hline \multirow[t]{2}{*}{ onusta baccis ambulat } & Onusta baccis ambulat \\
\hline & Baccae \\
\hline baccalaureatus, us & Baccalaureatus, ûs \\
\hline baccalaüreus, ej & Baccalaureus, ei \\
\hline baccalia & Baccalia, ae \\
\hline baccans & Baccans, tis \\
\hline baccantes papillae & Baccantes papillae \\
\hline baccaris vid. baccharis & Baccaris. V. Baccharis \\
\hline baccatus, a & Baccātus, a, um \\
\hline monile baccatum & Monile baccatum \\
\hline bacchae & Bacchae, arum \\
\hline bacchae bacchanti aduersari & Bacchae bacchanti adversari \\
\hline bacchanal & Bacchānal, ālis \\
\hline bacchanalia & Bacchanalia, um \\
\hline bacchanalia viuere & Bacchanalia vivere \\
\hline
\end{tabular}




\begin{tabular}{|l|l|}
\hline \multicolumn{1}{|c|}{ URTE $(c a .1715)$} & \multicolumn{1}{c|}{ DICTIONARIUM (1693) } \\
\hline bacchans & Bacchans, ntis \\
\hline homo bacchans & \\
\hline homines bacchantes & \\
\hline homo bacchans & in voluptate \\
\hline bacchans in voluptate & Bacchar, aris \\
\hline bacchar & Bacchātim \\
\hline bacchatim & more bacchantium \\
\hline bacchatim viuunt & Bacchātio, ōnis \\
\hline bacchatio & Bacchationes nocturnae \\
\hline i. bacchationes nocturnae & Bacchatus, a, um \\
\hline bacchatus, a [...] vid. bacchans & Ferro bacchatus \& igni \\
\hline ferro bacchatus et igni & Virginibus bacchata Lacaenis Taygeta \\
\hline virginibus bacchata laçaenis Taygeta & \\
\hline soror Taygeta & Bacche, es [...] V. Bacchae \\
\hline bacche. vid. bacchae & Utque suum Bacche non sentit saucia vulnus \\
\hline utque suum bacche non sentit sauçia vulnus & Bacchinal [...] id. quod Bacchanal. Vid. \\
\hline bacchinal. vid. bacchanal & Bacchius, ii \\
\hline bacchius & Bacchor, aris \\
\hline bacchari & \\
\hline bacchatur & \\
\hline
\end{tabular}

Queda en el aire la incógnita de cómo valorar aquellas entradas de la obra de Urte que no aparecen en el diccionario británico. Podríamos admitir, sin mayor dificultad, la posibilidad de cierta labor creativa en el religioso labortano que, aceptado tal supuesto, no se habría limitado a copiar miméticamente el diccionario de Cambridge. Pero tampoco nos atrevemos a descartar totalmente la idea de que otro hubiese sido realmente el diccionario que le hubiese servido de fuente.

\section{Las referencias a las obras de Urte en la correspondencia Chamberlayne - Leibniz}

En las personas de John Chamberlayne y de Gottfried Wilhelm Leibniz ${ }^{23}$ concurrían toda una serie de inquietudes comunes: su interés profesional en el estudio de la Historia, su condición -desde el año 1714- de servidores del rey Jorge I de Inglaterra, y su simultánea pertenencia a instituciones tan relevantes como la londinense Royal Society y la Sozietät der

23 La poderosa mente de Leibniz (Leipzig 1646 - Hannover 1716), si bien universalmente conocida por sus escritos filosóficos y matemáticos, abarcó prácticamente todos los ámbitos del conocimiento, entre ellos el de la lingüística. Su marcado interés en el estudio de las lenguas naturales comenzaría allá por el año 1685, fecha en la que el duque Ernesto Augusto de Hannover le encargó la elaboración de un estudio histórico acerca del ducado de Brunswick-Lüneburg. Las lenguas constituían una fuente muy importante para sus estudios históricos, puesto que, como el propio Leibniz (Couturat, 1903: 224-229) decía ya en 1686: «je tiens que de tout ce qui est non-écrit les langues mêmes sont les meilleurs et les plus grands restes significatifs de l'ancien monde, dont on pourrait tirer des lumieres pour les origines des peuples et souvent pour celles des choses». Es tras el largo periplo que desde noviembre de 1687 hasta junio de 1690 emprendió por Austria, Italia y el sur de Alemania en busca de materiales para su trabajo histórico, cuando Leibniz aborda ya de manera seria y profunda sus investigaciones lingüístico-positivas. 
Wissenschaften de Berlín ${ }^{24}$-de la que Leibniz era presidente-. Ambos estaban, además, vivamente interesados en el estudio de las más diversas lenguas del orbe, entre ellas, y de manera que en modo alguno podemos calificar de anecdótica, la vasca. Ya antes de que, en 1714, empezase a tratar con Leibniz acerca de dicha lengua, Chamberlayne le había encargado a Urte la redacción de una gramática de la lengua vasca. En cuanto a Leibniz, al menos desde el año 1691 venía solicitando -de manera casi siempre infructuosa- información acerca del euskara a un buen número de sus corresponsales. En lógica coherencia con su concepción filosófica de la harmonie préétablie, Leibniz indagaba acerca de la harmonie des langues, y la presencia de un idioma como el euskara, tan distante del resto de las lenguas europeas, le desconcertaba enormemente.

Salvedad hecha de alguna misiva aislada en el año 1710, la relación epistolar entre ambos eruditos -en su mayor parte inédita y que se conserva en la Gottfried Wilhelm Leibniz Bibliothek (en adelante GWLB) de Hannover- se circunscribe al periodo 1713-1715 y el euskara ocupa en la misma un lugar de cierta relevancia. De hecho, Chamberlayne fue uno de los escasos corresponsales de Leibniz que efectivamente se preocuparon por las inquietudes de éste hacia la lengua vasca.

Además del profundo respeto intelectual que a Leibniz se le profesaba en toda Europa, es muy posible que la que nosotros consideramos especial amabilidad y disposición de Chamberlayne para con Leibniz, se debiese simplemente a su coincidencia de intereses en cuanto al estudio del euskara. De todos modos, tampoco podemos obviar el hecho de que, justo en aquellas fechas, el elector de Brunswick-Lüneburg y patrón de Leibniz, Jorge Luis de Hannover, era coronado rey de Inglaterra con el nombre de Jorge I, y es posible que Chamberlayne quisiese estar bien posicionado ante el nuevo monarca trabando para ello estrechos lazos de amistad con Leibniz. Éste, por aquel entonces, estaba enzarzado con Isaac Newton en una agria disputa acerca de la paternidad de la invención del cálculo infinitesimal, y la práctica totalidad de los eruditos ingleses se habían posicionado en favor de su compatriota Newton. Ahora, ante las nuevas circunstancias sucesorias, no eran pocos los británicos que temían la triunfal entrada en Londres de un Leibniz vengativo amparado por el nuevo rey. Lo que sin duda todos debían ignorar es que las relaciones entre Leibniz y el elector Jorge Luis, si nunca habían sido buenas, en esos momentos eran poco menos que inexistentes.

\subsection{Chamberlayne a Leibniz, Petty France Westminster, 24-11-1713 (05-12-1713) ${ }^{25}$ [Fuente: Ms. de la GWLB, LBr. 149 Bl. 1]}

En las fechas en las que John Chamberlayne redactó esta carta, estaba ultimando la preparación de una obra que finalmente vería la luz en 1715 con el título de Oratio Dominica

\footnotetext{
24 En su origen denominada Kurfürstlich-Brandenburgische Sozietät der Wissenschaften y que, tras múltiples cambios de nombre producto de las vicisitudes políticas del país, es la actual Berlin-Brandenburgischen Akademie der Wissenschaften. Por esta entidad, además de Leibniz, han pasado figuras tan relevantes de la cultura germana y universal como Kant, los hermanos Grimm, Einstein y un larguísimo etcétera.

25 Los supuestos, como el presente, en los que el lector encuentre dos distintas fechas, responden a los diferentes calendarios vigentes en aquel entonces en Europa. En tales casos, la primera fecha corresponderá al calendario juliano y la segunda, entre paréntesis, al actual calendario gregoriano. Aunque este último estaba vigente en Hannover y en el resto de la Germania protestante desde el año 1700, en Inglaterra no entraría en vigor hasta el año 1752.
} 
in diversas omnium fere gentium linguas versa ${ }^{26}$. Además de la exhaustiva recopilación de padrenuestros -que se pretendía mejorase cuantitativa y cualitativamente las que hasta ese momento se habían editado al respecto-, Chamberlayne se proponía enriquecer su obra con una serie de «Discours ou Dissertations Epistolaires sur l'origine des Langues, leurs Relations ou Analogie, Changemens etc», escritas por los autores más doctos en ese campo del conocimiento. Estas disertaciones conformarían la segunda parte de su obra y, efectivamente, aparecieron en la misma bajo la rúbrica de Dissertationes ex occasione Sylloges orationum dominicarum scriptae ad Jo. Chamberlaynium. Cuando Chamberlayne escribe a Leibniz, ya habían confirmado su participación «le Dr Nicolson Eveque de Carlile, le Dr Wotton, [et] Mr le Professeur Relandus», y Chamberlayne, que consideraba a Leibniz como el hombre más versado en la materia, le solicita que haga lo propio:

je reprend la Plume pour vous dire Monsieur que j'ay preparé une nouvelle Edition de l'Oraison Dominicale (in centum fere linguis) et que j'ay ajouté un autre Centaine presque; mes Amis me flattent que j'ay redressé de Fautes et que ma Methode est plus utile que la derniere, et quelques uns des mes Sçavans Correspondants, comme le Dr Nicolson Eveque de Carlile, le Dr Wotton, Mr le Professeur Relandus, ont bien voulu enrichir mon Recueil par des Discours ou Dissertations Epistolaires sur l'origine des Langues, leurs Relations ou Analogie, Changemens etc [...] oserai-je vous prier aussi Monsieur d'y ajouter quelque petit Discours sur le meme sujet? vous qui peutetre entendez plus de ces versions là qu'aucun autre, et qui connoissez le Genie de Toutes? C'est une fort grande Hardiesse de vous le demander, mais en revange, je vous supplie de commander en toutes les occasions ou je vous pourrois etre utile.

\subsection{Leibniz a Chamberlayne, Viena, 10-01-1714}

\subsubsection{El fragmento de la carta publicado por Chamberlayne}

[Fuente: Chamberlayne, 1715: II, 22-30]

Leibniz cumple con el requerimiento de Chamberlayne en poco más de un mes y le remite una amplia e interesantísima disertación que éste incluiría en su obra con el título de «Dissertatio de variis linguis». El discurso de Leibniz estaba básicamente centrado en el estudio de los diferentes alfabetos o sistemas de signos de las diversas lenguas del mundo. Es tras escribir acerca de los caracteres que aparecen en algunas monedas hispanas reproducidas en una obra de Lastanosa ${ }^{27}$, cuando Leibniz (Chamberlayne, 1715: II, 25) habla del euskara:

Ipsam linguam veterum Hispanorum Biscainae vel Vasconicae hodiernae similem fuisse credibile est, quae sese in asperrimis montibus contra Romanos, Gothos, Saracenos tueri potuit. Et credibile est hanc linguam etiam se nonnihil per vicinam Galliam, Aquitanicam scilicet et Narbonensem diffudisse, sed a Celtica id est Gallica vetere et Germanica longe diversam esse apparet.

26 Vid. inf. $\$ 4$.

27 La obra editada por Lastanosa era el Museo de las medallas desconocidas españolas. Ya en 1697, Leibniz hablaba con Johan Gabriel Sparwenfeld del parecido de dichos caracteres con los de las runas y de la opinión contraria del autor de la obra, que proclamaba la exclusiva hispanidad de dichos caracteres achacando estas semejanzas simplemente al «Antojo, i Arbitrio de quien las delinea» (Lastanosa, 1645: A los lectores). 
Como vemos, Leibniz plantea en su texto la posibilidad de que la primitiva lengua de los hispanos hubiese sido similar a la vasca, especie de vestigio lingüístico que pudo subsistir a las invasiones de sucesivas civilizaciones por lo abrupto del territorio vasco. Expone también la probabilidad de que el ámbito geográfico de la lengua vasca hubiese sido mucho mayor en la antigüedad, ya que también pudo ser la lengua del sur de la Galia (Aquitania y Narbonense). Finalmente, señala su opinión acerca de la falta de conexión entre el euskara y las lenguas célticas y germánicas.

El hecho de que la carta-disertación de Leibniz apareciese publicada por Chamberlayne en su Oratio Dominica de 1715 y, posteriormente, fuese reproducida por Dutens ${ }^{28}$ (1768: VI $-2,195)$, motivó que tal vez haya sido ésta la cita de Leibniz sobre el euskara más conocida entre vascólogos y lingüistas en general. De entre éstos, debemos destacar al italiano Giuliano Bonfante (1953-1954: 694), quien -en un artículo además considerado como trascendental para los estudiosos de la historiografía de la lingüística- trasladó al inglés el anterior párrafo de Leibniz, diciendo respecto al mismo que: «What he says about basque is the best that can be said even today».

Aun siendo conscientes de que ha transcurrido ya más de medio siglo desde aquel «today» de Bonfante, no podemos por menos que estar de acuerdo con sus elogios, ya que en este breve párrafo de Leibniz aparecen condensadas toda una serie de consideraciones acerca de la lengua vasca que, por lo demás, son en buena medidas acertadas.

\subsubsection{El fragmento inédito de la carta}

[Fuente: Ms. de la GWLB, LBr. 149 Bl. 16-19]

En la carta original remitida por Leibniz a Chamberlayne, hemos encontrado un segundo párrafo que éste no editó en su obra de 1715 y que, por tanto, hasta ahora permanecía inédito:

Mirum est nondum Scripturam Sacram in Vasconum linguam Translatam haberi, neque etiam dictionarium linguae extare. Haec ergo viros doctos regionis incolas supplere optem. Nam fieri potest, ut multa lateant in antiquissima lingua quae res Europaeas illustrare possint.

En este fragmento de su misiva, Leibniz muestra su asombro y su pesar ante el hecho de que las Sagradas Escrituras no hubieran sido aún traducidas al vasco, así como que tampoco existiera ningún diccionario de dicha lengua, expresando a renglón seguido sus deseos de que algún erudito vasco reparase estas carencias. Al final del párrafo, Leibniz incide en la importancia que podría tener el estudio de una lengua tan antigua como la vasca, pues a través del mismo podría tal vez hacerse la luz sobre muchos asuntos que aún permanecían en tinieblas en el marco del ámbito lingüístico europeo. Ciertamente, y en la mayor parte de las ocasiones, ésta ha sido la causa por la que a través de los tiempos tantos ilustrados europeos se han acercado al estudio de la vieja lengua vasca.

Como veremos a continuación, Chamberlayne era sabedor de que el Nuevo Testamento ya había sido traducido al vasco en 1571, y ésta habría sido la razón por la cual habría optado por mutilar este párrafo de la carta de Leibniz.

28 De entre las numerosas ediciones recopiladoras de la obra del pensador germano, la que Dutens tituló Opera Omnia de Leibniz, fue la que más difusión alcanzó en el pasado. 


\title{
3.3. Chamberlayne a Leibniz, Petty France Westminster, 18-02-171449 $(01-03-1714)$
}

\author{
[Fuente: Ms. de la GWLB, LBr. 149 Bl. 12-13]
}

En esta carta, Chamberlayne le hace saber a Leibniz que, en contra de lo que él pensaba, ya existía una traducción al euskara del Nuevo Testamento, el Iesus Christ Gure Iaunaren Testamentu Berria de Leizarraga (1571), de la cual había un ejemplar en la Bodleian Library de Oxford ${ }^{30}$. Precisamente, Chamberlayne había transcrito de dicha obra una de las tres versiones que del padrenuestro en vasco habrían de aparecer en la Oratio Dominica de 1715.

Chamberlayne prosigue su misiva coincidiendo con Leibniz en el hecho de que, al menos hasta donde él sabía, nunca se había publicado gramática ni diccionario alguno de la lengua vasca. Pero sorprende a Leibniz con la noticia de que tiene empleado a un religioso vasco que le está elaborando una gramática de dicha lengua. Éste a quien describía como un «Poor Biscayan Priest (now a Protestant)» no era otro que Pierre d'Urte, artífice -amén de la gramática- de otra de las versiones del padrenuestro en euskara de la obra de Chamberlayne ${ }^{31}$.

Pero además, y ante el interés expresado por Leibniz hacia el euskara en su carta de enero de 1714, un Chamberlayne solícito en extremo, le sugiere la posibilidad-siempre que Leibniz estuviera de acuerdo- de que también Urte elabore un diccionario vasco, proporcionándole al religioso labortano algún diccionario latino o francés como guía para su trabajo:

\begin{abstract}
Viz what you mention about the Cantabrian Language, for I have seen the New Testament compleat in the said Language printed at Bourdeaux, about the middle of the last Century, and Dr. Hudson, Keeper of ye Bodleian Library was so kind as to lead me that in his Custody, from whence I transcribed one of the Versions of the Lord's Prayer, for another was given me before by a Poor Biscayan Priest (now a Protestant) whom I have out of Charity Employed in compiling a Grammar of this Language very copiously, and if you think fit, I will give him a good Latin or French Dictionary and make him Translate it into Basque, of which there is neither Gramar, nor Lexicon yet Extant in the World as I know of.
\end{abstract}

Aunque ya desde hace tiempo se suponía que habría sido Chamberlayne -también se pensó en su colaborador, David Wilkins- quien indujese a Urte a escribir sus obras vascas, tras la lectura de esta misiva la suposición pasa a ser certeza.

Sabemos así que, en marzo de 1714, Pierre d'Urte ya estaba trabajando en la elaboración «very copiously» de su gramática vasca. No sabemos cuándo empezó Urte su trabajo, ni tan siquiera cuándo lo terminó, pero a la vista de los datos aquí aportados, no parece del todo

29 En la carta manuscrita aparece, sin ninguna duda por error, 1713 en vez de 1714.

30 Vinson (1891: I, 14) nos refiere que fue John Selden (1584 - 1654) quien legó un ejemplar de esta obra a la Bodleian Library de Oxford; ejemplar que, sin duda, debió de ser el mismo que consultara Chamberlayne y que todavía hoy se sigue conservando en dicha biblioteca. Chamberlayne incurre en un leve error en cuanto al lugar de impresión, que no fue Burdeos sino La Rochelle. En realidad, Leibniz ya debería haber conocido la existencia de este trabajo. Sabemos que había leído con especial interés la obra Historia Studii Etymologici, escrita en 1711 por quien durante muchos años fuese su secretario, Johann Georg Eckhart. Prueba de ello es que fue precisamente su lectura la que motivó la redacción de su interesantísima Epistolica de historia etymologica Dissertatio (ca. 1712). Sin embargo, Leibniz debió de pasar por alto el pequeño capítulo que Eckhart dedicó en su obra a la lengua vasca bajo el título de "De Lingua veteri Cantabrica", pues en el mismo se hace clara referencia al Testamentu Berria de Leizarraga (vid. inf. § 5.2).

31 Vid. inf. $\$ 4.1$. 
correcta la fecha de 1712 con la que, de un modo un tanto arbitrario, Webster dató la Grammaire Cantabrique ${ }^{32}$.

\title{
3.4. Chamberlayne a Leibniz, Petty France Westminster, 27-02-1714 (10-03-1714)
}

\author{
[Fuente: Ms. de la GWLB, LBr. 149 B1. 20]
}

Chamberlayne le había remitido a Leibniz la carta que le había escrito el 18 de febrero por mediación de Heinrich Hasperg. Es entonces cuando este último pone a Chamberlayne al corriente del agrio enfrentamiento entre Leibniz y Newton a cuenta de la prioridad en la invención del cálculo infinitesimal. Por ello, pocos días después, el 27 de febrero, Chamberlayne le envía una nueva carta a Leibniz ofreciéndose como moderador en la disputa:

I send this to you by Mr. Hasberg an Agent for D. of Wolfenbuttel and who has the Honor to Correspond with you, it was from him that I have been informed of the Differences Fatal to Learning between two of the greatest Philosophers \& Mathematicians of Europe. I need not say I mean Sir Isaac Newton and Mr. Leibnitz, one of the Glory of Germany the other of Great Britain, and both of them Men that Honor me with their Friendship which I shall always Cultivate to the best of my Power, tho[ugh] I can never deserve it; now altho[ugh] I ought to say with the poet: Non nostrum est Tantas componere Lites, yet as it would be very Glorious to me, as well as Advantagions to the common Wealth of Learning, if I could bring such an Affair to a happy end, I humbly offer my Poor Mediation, and shall steem my self exceeding Happy if by this or any other Instance I can convince you with how great passion \& Truth.

Chamberlayne fue uno de los pocos británicos que, si bien no tomó abiertamente partido en dicha polémica en favor de Leibniz, al menos se mostró imparcial e, incluso, como estamos viendo, se ofreció para buscar el entendimiento «between two of the greatest Philosophers \& Mathematicians of Europe». La mediación no obtuvo frutos porque las posturas, sobre todo por parte de Newton, eran enconadas. Hoy, con el sosiego que aporta el transcurrir de los años y examinado el problema desde una perspectiva neutral y desapasionada, sabemos que ambos sabios descubrieron el cálculo infinitesimal por caminos paralelos y sin que mediara plagio por ninguna de las dos partes.

\subsection{Leibniz a Chamberlayne, Viena, $\mathbf{2 8}^{33}-04-1714$}

[Fuente: Des Maizeaux, 1740: II, 120-125. También en Dutens, 1768: III, 489-490]

Leibniz comienza su contestación a las dos anteriores cartas de Chamberlayne agradeciéndole a éste sus intentos de mediación:

32 Wentworth Webster incluyó la fecha de 1712 en el propio título de su trabajo: Grammaire Cantabrique Basque faite par Pierre D'Urte, 1712. La datación de Webster (1900: iii) es poco menos que caprichosa si nos atenemos a sus argumentaciones: «la grammaire a dû être commencée pendant les premières années du séjour de Pierre d'Urte en Anglaterre [nous ne savons pas en quelle année Pierre d'Urte est arrivé en Angleterre, mais en 1706, il était déjà en relations établies avec les personnes chez qui il travaillait comme philologue], et l'a occupé pendant un temps assez long, six ans peut-être, de 1706 à 1712».

33 En realidad, en la carta manuscrita que se conserva en la GWLB (LBr 149 B1. 21-22) nosotros leemos «21 d'Avril 1714». 
Je vous suis obligé [...] de votre offre obligeante de moyenner une bonne intelligence entre Mr. Newton \& moi [...] Si le mal pouvoït être redressé, Monsieur, par votre entremise à laquelle vous vous offrez si obligeamment, j'en serois bien aissé; \& je vous en ai déja beaucoup d'obligation par avance.

Después, Leibniz le transmite a Chamberlayne su profundo agradecimiento por el ofrecimiento de éste de elaborar un diccionario vasco. Está convencido (ya lo había expresado en otras ocasiones ${ }^{34}$ ) de que gracias al diccionario y, consiguientemente, al mejor conocimiento de la antiquísima lengua vasca, se podrían aclarar los topónimos de muchos lugares de España y de Francia. Leibniz, a través del minucioso examen de mapas geográficos, había observado la coincidencia entre muchos nombres de lugares a ambos lados de la cordillera pirenaica. Esto, unido al hecho de que Julio César ${ }^{35}$ había distinguido netamente a los aquitanos del resto de los pobladores de las Galias por sus leyes, por sus costumbres y, lo que aquí más nos atañe, por su lengua, le había llevado al convencimiento de que en Aquitania y en Vasconia debieron de hablarse en aquellos tiempos lenguas muy parecidas, si no la misma ${ }^{36}$.

Haciéndose eco de los autores que consideraban al vasco una lengua celta -teoría que él nunca tomó muy en serio- apunta a la posibilidad que proporcionaría el diccionario vasco de poder confrontar seriamente vasco y gaélico irlandés para confirmar o desechar definitivamente tales teorías.

34 Así en carta de 9-11-1695 (19-11-1695), Leibniz (Davillé, 1909: 412-413, nota) le hablaba a Simon de La Loubère de «la langue Cantabrique qui est commune aux Biscayens d'Espagne et à vos Basques. Je voudrois qu'on nous en donnât un dictionnaire, qu'on comparât cette langue avec d'autres, pour voir si on y decouvriroit quelque rapport soit à la langue Britannique, ou à l'Hibernoise, ou peutestre aux langues d'Afrique [...] Je serois sur tout bien aise de sçavoir si la connoissance de cette langue pourroit servir à expliquer bien manifestement les Etymologies des rivieres et des villes de ces pays là».

35 "I. Gallia est omnis divisa in partes tres: quarum unam incolunt Belgae, aliam Aquitani, tertiam qui ipsorum lingua Celtae, nostra Galli appellantur. Hi omnes lingua, institutis, legibus inter se differunt. Gallos ab Aquitanis Garumna flumen, à Belgis Matrona, \& Sequana dividit [...] Aquitania à Garumna flumine ad Pyrenaeos montes, \& eam partem Oceani, quae ad Hispaniam pertinet, spectat inter Occasum solis, \& Septentriones" (César, [ca. 50 a.C.] 1574: 1).

36 Como señala Susana Pastor (2001: 151-152) respecto de Leibniz: «la solidez de sus principios metodológicos se deja ver en el hecho de que fueran en parte adoptados en la futura investigación lingüística histórica. A través de tales métodos pudo llegar a afirmar respecto al vasco, por ejemplo, que su extensión fue mucho mayor que la que ocupaba en el momento (limitada a la zona comprendida entre la frontera franco-española de los Pirineos occidentales)». Además de en algunas de las misivas que integran su ingente producción epistolar -entre ellas la enviada a Chamberlayne y publicada por éste en 1715 (vid. sup. § 3.3.1)- esta idea de Leibniz también aparece expresada en alguna de sus obras impresas. Así, en la «Brevis designatio meditationum de originibus gentium», Leibniz (1710: 11) dice: «An potius vetus aliqua gens ex anteriore migratione, (priusquam illi adventarunt qui Celtas id est Germanos Gallosque sevêre) non Hispaniam tantùm sed \& Aquitaniam \& omnem viciniam tenuit, nam fluminum communia vocabula favent". También, en parecido sentido, en el escrito que su editor, Eckhart, tituló "De migrationibus celtarum" (Leibniz, [ca. 1711] 1717: I, 148): “et an credibile sit, Celtas, cum ex Germania venientes Rheno transmisso se in Galliam effudêre, habitatores anteriores in ea invenisse, lingua utentes Cantabricae cognata; in regionibus praesertim trans Ligerim sitis. Itaque cum Caesar Gallos in Belgas, Celtas \& Aquitanos distinguat; verisimile est, Celtas illos stricte dictos fuisse antiquam emissionem Germanicorum populorum, Belgas recentiorem; at Aquitanos, incolas anteriores, plus ex Vasconico traxisse. Et sane in ulteriori illa Gallia, nempe in provincia Narbonensi, Septimania \& Aquitania multa nomina locorum propria Nominibus propriis locorum Hispanicis conspirant; quod non exiguum est indicium, etiam antiquos habitatores cognatos fuisse". 
Finalmente, y una vez enterado de la existencia de la traducción al euskara de los Evangelios, plantea lo conveniente que sería que también se vertiese a dicha lengua el Antiguo Testamento ${ }^{37}$ :

Vous rendrez, Monsieur, un service considérable au Public, en faisant travailler à un Dictionnaire de la Langue Biscayenne, qui est si ancienne, \& dont la connoissance serviroit à éclaircir les noms propres de beaucoup de Lieux, non seulement en Espagne, mais encore dans la France voisine; car je vois qu'il y a des noms des Rivières, de Montagnes, \& de Villes ou de Villages, communs à l'Espagne \& à la France Méridionale, où je soupçonne que la Langue des Aquitains du temps de César, distinguée par luy-même de celle de la Gaule Celtique, a eu quelque chose d'approchant de la Biscayenne. Et il sera aussi fort important d'examiner, s'il n'y a pas dans l'Hibernois quelque chose du Biscayen. La Langue Biscayenne mériteroit bien aussi que la Bible, c'est à dire, le Vieux Testament fût traduit; puisque vous m'apprenez que le Nouveau s'y trouve déja.

Chamberlayne recoge el guante lanzado por Leibniz y encarga a Urte -que, por aquel entonces, suponemos ya debía de tener prácticamente finalizada su Grammaire Cantabriquela elaboración del diccionario y la traducción del Antiguo Testamento.

\subsection{Chamberlayne a Leibniz, Petty France Westminster, ¿22-05-1714? (¿02-06-1714?) [Fuente: Ms. de la GWLB, LBr. 149 Bl. 26]}

El 22 de mayo de 1714, Heinrich Hasperg ${ }^{38}$ había redactado una carta para Leibniz y en la posdata de la misma le comunicaba que, dos días antes, Chamberlayne le había hecho saber que le iba a entregar una misiva para él. Aunque Chamberlayne se demoró en su entrega, finalmente debió hacerla efectiva y, así, Hasperg ${ }^{39}$ pudo finalizar la posdata de su carta diciendo: «voicy la lettre encor de Mr. Chamberlain».

Pocos días antes, Chamberlayne había traducido al inglés la carta que Leibniz le había remitido el 28 de abril ${ }^{40}$ y que, recordemos, versaba sobre la polémica entre éste y Newton acerca de la prioridad en el descubrimiento del cálculo infinitesimal y en la que también se hablaba sobre la lengua vasca. En el Journal Book manuscrito de la Royal Society -que venía a ser algo así como el libro de actas de dicha sociedad-, con fecha 20 de mayo, queda reflejada la postura de la entidad de no tomar en consideración la carta de Leibniz por no estar

37 La carta de Leibniz permite datar con mayor precisión la traducción parcial de la Biblia por Urte, que ya no sería -como imprecisamente apuntaba Thomas en el propio título de su edición- ca. 1700 sino, más bien (y como el Dictionarium Latino-Cantabricum), ca. 1715.

38 Hasperg se encargó, mientras estuvo en Londres, de remitirle a Leibniz las cartas de Chamberlayne. Tendremos ocasión de volver a hablar de él más adelante (vid. inf. § 5.3).

39 Carta de Hasperg a Leibniz enviada desde Londres el 22-05-1714 (02-06-1714), Ms. de la GWLB, LBr. 374 B1. 22-24. La posdata (B1. 24) reza así: «Monsieur Chamberlain me dit avanthier qu'il me vouloit envoyer une lettre pour votre Excellence, mais il ne l'a pas fait, peut etre qu'il sera trop occupé aujourdhui. Il me dit aussi qu'il avoit vu quelque papier imprimé peut etre à Vienne touchant votre dispute avec Mr. Newton, ce qui avoit eu quelques expressions piquantes, il croit qu'il seroit mieux d'apaiser cette dispute et qu'il contriburoit de sa part à une bonne harmonie, come etant bon Ami de Votre Excellence et de Monsieur Newton [...] Voicy la lettre encor de Mr. Chamberlain». 40 La traducción de dicha carta se conserva en los archivos de la Royal Society (Ms. de la London R. S. Library and Archive, EL[Early Letters]/L5/113, 1714). 
formalmente dirigida a la sociedad. Pero, además, y a renglón seguido, se toma nota de las observaciones de un miembro de la Royal Society, Robert Keck ${ }^{41}$, referidas a la sorprendente revelación de que su sirviente irlandés podía entenderse sin mayor dificultad con los vascos.

En la GWLB hay un «Extract from the Journal of the Royal Society May 20, 1714» que reproduce casi milimétricamente el contenido del Journal Book. Parece lógico pensar que este extracto es «la lettre» que el 22 de mayo ${ }^{42}$-esto es, sólo dos días después de la reunión de la Royal Society - Hasperg anunciaba a Leibniz que le remitía «Mr. Chamberlain»:

Extract from the Journal of the Royal Society

May 20, 1714

Upon mention made in a Letter from Mr. Leibnitz to Mr. Chamberlayne of the agreement between the Biscain \& Irish Languages Mr. Keck said that being in Spain after the Battel of Almanza he had and Irish Servant with him, who conversed without much difficulty with the Natives of the Province of Biscainy.

Desconocemos si Chamberlayne -como, por otro lado, solía hacer ${ }^{43}$ - acompañó el «Extract» de alguna otra nota, siquiera fuese a modo de saludo. La lógica nos dice que así debió ser y que, en tal caso, lo fácil es que hubiese comprendido alguna observación sobre la lengua vasca, bien referida a la última misiva de Leibniz, bien relativa a las afirmaciones de Keck. En cualquier caso, si tal nota existió, debemos de darla por perdida, una vez examinadas todas las cartas manuscritas que, atribuidas a Chamberlayne, se conservan tanto en la GWLB como en la Royal Society.

\subsection{Leibniz a Chamberlayne, Viena, 25-08-1714}

[Fuente: Des Maizeaux, 1740: II, 128-129. También en Dutens, 1768: III, 491-492]

Tras un nuevo y breve agradecimiento a Chamberlayne, Leibniz pasa a hablar de la lengua vasca. Fiel a su libertad de pensamiento, no parece que otorgue demasiada credibilidad a la historia de Keck, a pesar de provenir de un miembro de la prestigiosa Royal Society que, además, relata el hecho como testigo directo del mismo ${ }^{44}$. Pocos años antes, Edward Lhuyd

41 Robert Keck (ca. 1686 - 1719) acababa de ser nombrado en aquel entonces miembro de la Royal Society.

42 El manuscrito ha sido datado provisionalmente por la GWLB como de mayo de 1714, sin mayores especificaciones. Ciertamente, la cuestión es compleja, porque a partir de una única página del Journal Book, Chamberlayne hace dos extractos diferentes y parece que se los envía a Leibniz en fechas también diferentes. El que hace referencia a la lengua vasca lo habría enviado el 22 de mayo y el relativo a la polémica con Newton (Ms. de la GWLB, LBr. 149 B1. 27) lo remite probablemente en agosto -aunque, también provisoriamente, la GWLB lo fecha simplemente como «nach juli 1714»-. Por alguna razón que desconocemos, Chamberlayne no quiso o no se atrevió a comunicarle a Leibniz en mayo el fracaso de sus gestiones ante la Royal Society.

43 Así lo hizo, por ejemplo, a modo de posdata cuando allá por agosto de 1714 (Ms. de la GWLB, LBr. 149 Bl. 28) le remitió el segundo «Extract».

44 Al parecer, era un chisme recurrente lo de las personas que podían entenderse hablando en vasco y en las diversas lenguas célticas. Los autores pretendían, además, dotar de mayor verosimilitud a tales noticias arrogándose el papel de testigos presenciales del prodigio. Aparte de la información de Keck, Bruzen de la Martinière (1730: t. II, vol. III, 440) expresó algo parecido en su obra Le Grand Dictionnaire géographique et critique: «Celtes. On pourroit demander en quel lieu on peut retrouver des restes de la Langue Celtique. On pretend qu'elle s'est conservée dans la Bretagne Province de France; au Pays de Galles en Angleterre, \& dans la Biscaye en Espagne. Leur Langue est la même, ou plutôt ce sont trois Dialectes d'une même Langue, ce qui se prouve parce qu'avec un peu d'attention 
afirmaba fuera de toda duda en su Archaeologia Britannica de 1707 -obra que, por otro lado, Leibniz ponderaba ${ }^{45}$-, el parentesco entre el vasco y las lenguas célticas. Otras voces afirmaban lo mismo, pero Leibniz, basándose en un dato tan objetivo como es la observación de «les essais que l'on voit des deux Langues», no acaba de transigir con dicha teoría:

Je vous suis obligé de la tentative que vous avez faite à la Societé Royale [...] Ce seroit beaucoup si la Langue Irlandoise étoit si voisine de la Biscayenne, que les gens de l'un $\&$ de l'autre Pays se pussent entendre sans beaucoup de difficulté; comme on l'a rapporté à la Societé Royale. Cela ne paroît point par les essais que l'on voit des deux Langues. Peut-être est ce que le Garçon Irlandois avoit déja conversé autrefois avec des Biscayens. Cependant la chose mérite une plus ample discussion, \& seroit de conséquence si elle se pouvoit vérifier.

\subsection{Incógnitas sin despejar}

El estudio de la correspondencia entre Leibniz y Chamberlayne nos ha permitido demostrar que fue este último quien formalmente encargó a Urte la redacción de sus obras y quien le proporcionó los libros que habrían de ser la fuente de sus traducciones. Pero habría sido Leibniz, sin embargo, quien motu proprio sugiriese a Chamberlayne la conveniencia de la traducción al euskara del Antiguo Testamento y quien -en este caso tras el ofrecimiento de Chamberlayne- ponderase las bondades que resultarían de la existencia de un diccionario de la lengua vasca.

Aunque la relación epistolar entre ambos eruditos no se agota en las cartas que aquí hemos estudiado, ya nunca volverán a tratar en su correspondencia ni de las obras de Urte ni de la lengua vasca. Si bien es posible que siguiesen abordando el tema en alguna otra misiva que podría haberse extraviado ${ }^{46}$, el hecho cierto es que este silencio deja abiertas muchas

ces trois peuples se peuvent entendre. Je l'ai éprouvé moi-même un jour que j'avois chez moi un Gentil-homme bas Breton, un Voyageur du Pays de Galles, \& un Biscayen, chacun d'eux croioit sa Langue inintelligible à tout autre qu'à ses compatriotes. Ils en firent l'essai \& furent surpris de pouvoir s'entendre, se parler les uns aux les autres». Posteriormente, Jean-Baptiste Bullet (1754: I, 19), como apoyo a sus tesis de considerar el vasco como un dialecto céltico más, reproduciría literalmente la información de La Martinière en su obra Mémoires sur la langue celtique. También Francis Wise (1758: 30, nota) se hace eco de una anécdota parecida, según la cual un religioso irlandés se entendía perfectamente con los baserritarras vizcaínos hablando, respectivamente, gaélico y euskara: «one Mr Hutchins of Frome, just come into England out of Spain from Bilboa, where he had belonged to the Factory the better part of Twenty years; who among other things told us; That while he was there [...] came over to Bilboa an Irish Roman Catholic priest, that knew neither English, nor Spanish. When the person, to whom he was recommended, being at a loss what to do, brought him to the English Factory; to see if any one there understood Irish, but to no purpose: till some Mountain Biscainers, that used Bilboa Market, coming to the house where he lodged, and talking together, were perfectly understood by Him: and on his accosting them in Irish, he was as well understood by Them; to the great surprize of all that knew it, as well Spaniards as English. The narratour of this fact in his own knowledge, I am satisfied, was too sensible to be imposed on himself, and too honest to impose on others; and as he was no scholar, he had no hypothesis to serve».

45 Leibniz ([ca. 1711] 1717: I, 153), quien utilizó para sus estudios la obra de Lhuyd, dice a propósito del autor galés: «Postremo ad perficiendam vel certè valde promovendam Literaturam Celticam, diligentius linguae Hibernicae studium adjungendum censeo, ut Lloydius egregiè facere coepit».

46 Entre la inmensa mole de manuscritos leibnizianos se encuentran las aproximadamente 15.000 cartas que componen la vasta correspondencia de Leibniz con cerca de 1.100 distintos corresponsales. Si bien Leibniz trató de conservar su correspondencia, son muchas las cartas que se extraviaron y que debemos dar por perdidas. En carta a 
interrogantes acerca del devenir de los trabajos de Urte. Sabemos que, salvedad hecha de su gramática, Urte interrumpió la redacción del resto de sus obras, pero desconocemos el cuándo y el porqué ${ }^{47}$. Dado que inició sus trabajos a instancias de Chamberlayne y a cambio de una ayuda económica, cabría pensar que los habría abandonado al cesar dicha subvención ${ }^{48}$. Aun suponiendo que así hubiese sido, la ausencia total de datos acerca de las posibles motivaciones que justificasen este proceder de Chamberlayne, nos obliga a dejar todas las incógnitas abiertas, pues lo contrario sería entrar de lleno en el terreno de la elucubraciones.

\section{El padrenuestro de Urte y otras alusiones a la lengua vasca en la Oratio Dominica in diversas omnium fere gentium linguas versa de Chamberlayne (1715)}

Pese a algunos errores e inexactitudes, es de justicia reconocer los esfuerzos de Chamberlayne y de su colaborador, David Wilkins ${ }^{49}$, en la preparación y edición de esta obra que, en nuestra opinión, superó a todas las que hasta el momento se habían publicado en su género. Además, el alto nivel de los ensayos que Leibniz y otros ilustres eruditos escribieron para la segunda parte del libro, contribuyeron en muy buena medida a la grandeza de la obra ${ }^{50}$.

En cuanto al euskara, en la Oratio Dominica de 1715 aparecen tres distintas versiones del padrenuestro en dicha lengua, una de ellas atribuible a Pierre d'Urte. Hay también -además del párrafo de Leibniz del que ya hablamos ${ }^{51}$ - tres autores que hacen breve referencia a la lengua vasca en las disertaciones que integran la segunda parte de la obra.

Andreas Morell de 31-05-1697, el propio Leibniz (Bodemann, 1889: 190) reconoce que "la multitude de mes papiers et de mes soins partagés entre trop de choses fait que des lettres, auxquelles je dois response, s'égarent quelques fois". Davillé (1909: 460) se hace eco de esta y otras afirmacioness de Leibniz para concluir que "l'ordre n'était pas trop dans ses habitudes, ni surtout dans ses moyens, il égarait ses lettres et ses notes de toutes sortes".

47 No parece probable la afirmación de Thomas (1894: xx) de que hubiese sido la muerte de Urte la que provocó la interrupcion de sus obras: "The work may, of course, have been cut off abruptly by the translator's death".

48 Urte dejó de recibir en octubre de 1719 la ayuda económica que Inglaterra prestaba a los hugonotes franceses (vid. sup. nota 11). Aunque Chamberlayne era miembro de la comisión que decidía acerca de la pertinencia o no de tales ayudas, no creemos que esta circunstancia tenga necesariamente que guardar relación con la retribución que, ésta a título personal, Chamberlayne prestaba a Urte a cambio de sus traducciones vascas.

49 David Wilkins (1685 - 1745) fue un orientalista prusiano - parece ser que su apellido original fue Wilke- afincado desde su juventud en Inglaterra. Amén de su trabajo - desde 1715-como bibliotecario de la Archiepiscopal Lambeth Palace Library, en la época de la edición de la obra de Chamberlayne, Wilkins estaba centrado en el estudio del copto, más concretamente en la traducción a dicha lengua del Nuevo Testamento, trabajo que culminó en 1716 con la publicación en Oxford del Novum Testamentum Aegyptium, vulgo Copticum. Sobre dicha lengua versaría también la disertación que Wilkins insertaría en la segunda parte de la Oratio Dominica de 1715. Posteriormente, en 1717, se graduaría como doctor en Teología en la Universidad de Cambridge, institución en la que prestaría sus servicios como profesor de árabe. Pastor de la iglesia anglicana, llegó a ser archidiácono en Suffolk. Tal vez su obra más importante fuese la editada en Londres en 1737 con el título de Concilia Magnae Britanniae et Hiberniae.

50 Estos fueron, por orden de aparición, los diferentes autores que contribuyeron con sus disertaciones a la segunda parte de la obra de Chamberlayne: William Nicolson (de Universis totius orbis Linguis); Gottfried Wilhelm Leibniz (de Variis Linguis); Wilhelm Surenhus (de Oratione Dominica Hebraica); William Wotton (de Confusione Linguarum Babylonica); David Wilkins (de Lingua Coptica); Adrien Reland (de Veteris Linguae Aegyptiacae); Mathurin Veyssière de Lacroze (de Variis Linguis); Johann Joachim Schröder (de Rebus Armenicis); y Jezreel Jones (de Lingua Shilhensi).

51 Vid. sup. § 3.2.1. 


\subsection{El padrenuestro de Pierre d'Urte}

David Wilkins fue el autor del amplio "Praefatio" a la obra de Chamberlayne. En el mismo, y con respecto a las tres versiones del padrenuestro en euskara, Wilkins explica que la primera de ellas está extraída del ejemplar del Testamentu Berria (1571) de la Bodleian Library ${ }^{52}$. En cuanto a la segunda, Wilkins la atribuye por error al "Dominus Petrus d'Urte". Aunque tanto Thomas (1894: xvi) como Vinson (1897: 21-22) ya llamaron en su día la atención sobre este yerro ${ }^{53}$, los críticos posteriores han seguido considerando -pensamos que equivocadamente- que es ésta la versión de Urte. Finalmente, y por lo que a la tercera versión del padrenuestro se refiere, Wilkins dice que les fue comunicada por un amigo vasco, haciendo notar el hecho de que coincide prácticamente en todo con la que aparece en el libro "petit Miroir de devotion" (Debocino escuarra, mirailla eta oracinoteguia) de Haramburu:

Cantabricam primam pl. Reverendus \& Clarissimus Dominus Doctor Hudsonus Bibliothecae Bodelejanae \& Aulae S. Mariae apud Oxonienses Praefectus dignissimus ex Nov. Test. Biscaino sive Cantabrico Rochellae 1571. 8. impresso Domino Chamberlaynio misit; Cantabricam secundam sive stylo Incolarum St. Johannis de Luz Dominus Petrus d'urte Cantaber ex oppido S. Johannis de Luz in provincia nuncupata Labour in Biscaia oriundus conscripsit. Cantabricam tertiam Amicus Cantaber nobis communicavit, quae in omnibus fere coincidit cum Oratione Dominica libro petit Miroir de devotion par Jean Haramboure Burdigalae 1635. inserta.

Nosotros creemos que realmente es la tercera versión la única que puede atribuirse a Urte, y que él debe ser el "Amicus Cantaber" al que hace referencia Wilkins. En la Grammaire Cantabrique, Urte (Webster, 1900: 13) nos ofrece dos versiones del "Notre Père, en Langue Cantabrique", y la segunda, "sans tutoyer au singulier", concuerda casi absolutamente con la tercera de las descritas por Wilkins y reproducidas por Chamberlayne. Cierto es que, como dice Wilkins, dicha versión también coincide prácticamente en todo con la aportada por Joanes Haramburu en su obra Debocino Escuarra, pero no olvidemos que Haramburu era, como

52 Como en su día hiciera Vulcanius (1597: 92), también Chamberlayne (1715: I, 43) reproduce -de entre las distintas versiones que hay en la obra de Leizarraga- el padrenuestro que aparece en S. Mateo vi, 9-13. Ahora bien, la gran diferencia entre ambos autores es que la reproducción de Chamberlayne fue cuidadosa y carece de erratas (la única, si acaso, es que entiende el ceruëtã de Leizarraga como ceruëtam cuando lo correcto sería ceruëtan), mientras que la de Vulcanius no lo fue tanto. Los yerros cometidos por Vulcanius fueron además incrementándose en número por los recopiladores de padrenuestros que utilizaron al autor flamenco como fuente y el resultado, con el transcurso de los años, fue un padrenuestro en vasco prácticamente irreconocible a causa de los sucesivos errores acumulados. Hay un espléndido artículo de Francisco J. Oroz (1980: 3-23) que aborda en profundidad el tema.

53 Thomas (1894: xvi) dijo en este sentido: "A singular mistake is made here. The second Pater Noster is not in the dialect of St. Jean de Luz, but in Souletin. The third version is in Labourdin (St. Jean de Luz), but is not quite the same as that given by D'Urte in his grammar". Reproducimos esta segunda versión tal y como apareció recogida por Chamberlayne (1715: I, 44): “Cantabrice, stylo Incolarum St. Johannis de Lutz: Goure' aïta cerietan cirena, sanctificatudela çoure' icena, çoure' erresuma heldadila çoure' borondatia eguindadila lurrian cerien beçala, emaneçaguçu egun eguneco oguia, barkhaçaguçu goure' ekhatiac guc goure' ofensaçaler barkhacendugun beçala, Eta esquitçaceula utci tentationétala errortera bena deliberaguit çaçu gaïtcetarik. Halabiç". 
Urte, labortano, concretamente de Sara (Sare), y no puede extrañarnos que los padrenuestros de uno y otro autor se asemejen ${ }^{54}$.

De esta manera -con alguna que otra errata- reprodujo Chamberlayne (1715: I, 44) el que pensamos es, en definitiva, el padrenuestro atribuible a Urte:

Cantabrice, stylo comuni: Gure Aita keruétan caréña, erabilbedi sainduqui çure Jcena, ethorbedi çure Erressuma, eguinbedi çure Borondatea çeru'an becala lurre'an ere, emandieçagucu egun gure egunorozco oguia eta barkhadietcagutçu gure çorrac gucere gure cordunei barkhatcendiotçaguten becala, eta ezgaitçatcu utc tentacionétan erortcerat, aitcitic beguiragaitcatçu gaitc gucietaric. Halabiz.

\subsection{Las menciones al euskara en las «Dissertationes ex occasione Sylloges Orationum dominicarum scriptae ad Joannem Chamberlaynium»}

\subsubsection{William Nicolson}

[Fuente: Chamberlayne, 1715: II, 1-21]

Una de las primeras personas a las que Chamberlayne solicitó su colaboración para la segunda parte de su obra, fue a su amigo y socio en la Royal Society, William Nicolson ${ }^{55}$. La disertación de éste tenía como título "De universis totius orbis linguis", y le fue remitida a Chamberlayne el 22 de diciembre de 1713 desde Rochester.

La Archaeologia Britannica de Edward Lhuyd es la fuente de las opiniones de Nicolson en cuanto al euskara ${ }^{56}$. Así, Nicolson (Chamberlayne, 1715: II, 15) habla de la afinidad entre

54 Urte (Webster, 1900: ix) decía precisamente al inicio de su Grammaire Cantabrique que el euskara hablado en Sara y en su natal Donibane Lohizune era el mejor de todo el País Vasco: "De Toute la Cantabrie francoise où l'on parle le meilleur basque c'est dans la province de Labour, qu'on nomme Laphurdi, et surtout a St Jean de Luz et a Sara deux paroisses de cette province distantes de deux petites lieues l'une de l'autre". Así aparece reproducido el padrenuestro en la obra del autor de Sara, Haramburu (1635: 3-4): "Gure Aita ceruetan çarena, erabil bedi sainduqui çure Icena. Ethor bedi çure erresuma. Eguin bedi çure borondatea, ceruan beçala lurrean ere. Iguçu egun gueure egunorozco oguia. Eta barkha diatçagutçu gueure faltac guc gure gana falta dutenei barkhatcen derauztegun beçala. Eta ezcaitçatçula utz tentamendutan erortera. Aitcitic beguira gaitçatçu gaitcetic. Biz hala".

55 William Nicolson (Plumbland 1655 - Londonderry 1727), cursó sus estudios superiores en el Queen's College de Oxford, culminando su currículo en 1702 al alcanzar el más alto grado académico británico con el título de $D i$ vinitatis Doctor tanto por la Universidad de Oxford como por la de Cambridge. Fue obispo de Carlile desde 1702 y de Derry desde 1718, y era miembro de la Royal Society desde 1705. Profundamente interesado en el estudio de las lenguas, William Nicolson fue uno de los principales valedores tanto de George Hickes como de Edward Lhuyd, autores de algunas de las obras lingüísticas más relevantes editadas a principios del s. XVIII. Además, en su libro The Irish Historical Library (1724), incluiría, traduciéndolos al inglés, el prefacio galés y el irlandés de la Archaeologia Britannica de Lhuyd, consiguiendo así hacerlos más asequibles para la generalidad de los lectores.

56 A grandes rasgos, la teoría de Lhuyd (1707: At I Kimri) se basaba en la esencial unidad de las lenguas celtas, a pesar de la gran cantidad de vocablos diferentes entre las mismas. Lhuyd achacaba estas diferencias a que parte de los pobladores de Irlanda, los escotos, habían llegado allí desde Hispania, y habían traído con ellos su lengua: el antiguo español o vasco. De este modo, el autor galés consideraba que una buena parte de la lengua irlandesa era efectivamente conciliable con la galesa, mientras que la otra parte lo era con el vasco. Éstas habrían sido las palabras de Lhuyd, según traducción del propio Nicolson (1724: 224): "so by a diligent Perusal of the New Testament, and some Manuscript-papers I received from the learned Doctor Edward Brown, written in the Language of the Cantabrians, I have had a satisfactory Knowledge as to the Affinity of the other Part with the old Spanish. For though a great deal of that Language be retained in the present; yet much better preserved do we find it, amongst the Cantabrians". 
las distintas lenguas celtas, incluyendo al vasco entre las mismas; afinidad que hace extensible a los numerales, que Lhuyd ${ }^{57}$ había tomado de Vulcanius (1597: 96):

Quod praecipuae veteris hujus linguae reliquiae in Wallia, Cornubiâ, \& Britannia inferiori restent, facilè concedi potest, modò Hibernos, Biscayanos, \& Scotos Montanos suis hujus Linguae Dialectis non fraudemus. Inter has omnes, praesertim inter Cantabricam \& Hibernicam certissimam proximamque affinitatem esse mirifice probavit acutissimus Lluydus; qui insuper obiter observavit apud Celtas \& Hibernos (Keilt \& Guidhelod) nomine \& re unum idemque esse; \& quod Bon. Vulcanii Numeralia in Cantabrica Gascogniae Dialecto merè Wallica sunt.

\subsubsection{William Wotton}

[Fuente: Chamberlayne, 1715: II, 37-75]

También William Wotton ${ }^{58}$, en carta enviada desde su rectoría de Milton el 25 de noviembre de 1713, respondió prontamente a los requerimientos de Chamberlayne. Su largo y elaborado discurso sería insertado por éste en la segunda parte de su obra con el título de "Dissertatio de confusione linguarum, exstructoribus Turris Babylonicae a Deo inflicta".

En su disertación, de la que también hay una versión en inglés ${ }^{59}$, Wotton expresa una idea que sería fundamental en la lingüística comparativa del s. XIX, pero que resulta un tanto ana-

57 Lhuyd (1707: 269) había ensayado una curiosa explicación del significado de los números en euskara a través de su presunto parecido con determinados vocablos célticos: "There's nothing wherein Languages more Generally agree, than in the Numbers; and yet, excepting in one or two words, we find no Agreement from One to Ten in the Basque or Cantabrian (which we find thus in Vulcanius, Bat, bi, iru, lâu, bost, sey, shashpi, shorci, vedraci, amar), with any other European Language. Whether Bat may be out $\uparrow$ Baut (the Thumb), Bi, bîs (a Finger), iru, hirvis, verpus (the long Finger), Lau, lau (a Hand), Bost, Post, which in the Bohemian signifies the Fist: And whether Amar (Ten) may be from the Irish uilmir (all the Fingers)".

58 El religioso británico William Wotton (Wrentham 1666 - Buxted 1727) fue un niño de una precocidad extraordinaria, pues si a la edad de seis años ya era capaz de traducir versículos de la Biblia en latín, hebreo, griego e inglés, sólo tres años después ingresaba en el Catharine Hall de la Universidad de Cambridge, donde se graduó en 1679. Por aquellas fechas, ya había adquirido el dominio -amén de las lenguas antes citadas- del árabe, sirio y caldeo, además de profundos conocimientos de filosofía, matemáticas, geografía e historia. Wotton prosiguió sus estudios en el St. John's College, también de Cambridge, obteniendo el grado de Doctor of Divinity (Divinitatis Doctor) en 1707. En el ámbito de los estudios lingüísticos, Wotton publicó en 1708 su Linguarum vett. septentrionalium thesauri grammatico-critici et archaeologici, auctore Georgio Hickesio, conspectus brevis, epítome sobre la obra que George Hickes había publicado en 1703 y 1705. La época en la que Wotton escribió y remitió a Chamberlayne su discurso, fue, curiosamente -y sin que ello afectase a la calidad de su disertación-, la más penosa de su vida. Acuciado por las deudas, Wotton se dio a la bebida, frecuentando locales considerados como de mala reputación y protagonizando numerosos escándalos y altercados. Sus feligreses elevaron numerosas protestas ante sus superiores y, a finales de 1714, fue obligado a abandonar su suntuosa rectoría de Milton. Wotton se trasladó a Camarthen, en Gales, donde al parecer reordenó su vida, pagando sus deudas, abandonando la bebida y volviendo a sus estudios. Allí se interesó vivamente por la lengua galesa, que llegó a dominar en el breve periodo de dos años. Aunque, ya rehabilitado, Wotton regresó a Inglaterra en 1722, el idioma galés sería el protagonista de sus últimos estudios, que consistieron en la traducción al latín de un conjunto de viejas normas jurídicas galesas (la obra sería póstumamente publicada en 1730 con el título de Leges Wallicae ecclesiasticae et civiles). 59 La disertación de Wotton aparecería póstumamente publicada en inglés, en 1730, con el título de $A$ discourse concerning the confusion of languages at Babel... Now first publish'd from his original manuscript. Aunque los editores indican expresamente en el propio título de la obra que es su primera publicación, es evidente que no es sino una versión en lengua inglesa de la carta que, escrita en latín, dirigiera a Chamberlayne en noviembre de 1713. Ambas versiones, latina e inglesa, son obra de Wotton, siendo lo más probable que la redactada en su lengua materna 
crónica, por avanzada, en el año 1713. En una época en la que para decidir entre la afinidad entre varias lenguas se recurría exclusivamente a las semejanzas léxicas, Wotton (Chamberlayne, 1715: II, 67) pone de relieve la decisiva importancia, a tales efectos, de la comparación de las reglas gramaticales ${ }^{60}$ :

Argumentum siquidem meum non dependet à differentia verborum sed Grammaticae inter duas linguas, unde fit ut voces ab una in aliam deriventur linguam, derivataeque mutentur $\&$ formentur juxta particularem genium linguae in quam transferentur.

Pero volviendo al núcleo fundamental del trabajo de Wotton, éste expresa su firme convicción de que la patente diversidad de lenguas es obra del Creador en tanto que casa perfectamente con el episodio bíblico de la construcción de la Torre de Babel y el subsiguiente castigo divino. Wotton, no obstante lo anterior, hace especial hincapié en el hecho de que ello no significa que el actual mapa lingüístico coincida con el de aquel momento bíblico, puesto que son muchas las lenguas que han ido surgiendo con el transcurso del tiempo -expone, entre otros muchos, el caso de los distintos idiomas que han ido naciendo a partir del latín-. Wotton cree que pudieron ser dos, al menos, las lenguas nacidas tras el episodio de Babel. Habla a tal efecto de las lenguas orientales y de las occidentales, irreconciliables entre sí. Dentro de estas últimas, expone las evidentes coincidencias entre el griego, las lenguas latinas y las lenguas germánicas. En cambio, Wotton (Chamberlayne, 1715: II, 59-60) ${ }^{61}$ opina que las lenguas eslavas, el finés y el húngaro quedarían fuera de ese protogrupo de lenguas europeas, mientras que no se atreve a pronunciarse sobre las lenguas celtas y el vasco:

fuese la que primero escribiese Wotton, antes de pulirla y traducirla al latín, lengua culta de la época y en la que se escribieron todas las aportaciones que aparecieron en la obra de Chamberlayne.

60 Así aparece en la versión inglesa de su disertación: "My Argument does not depend upon the Difference of Words, but upon the Difference of Grammar between any two Languages; from whence it proceeds, that when any Words are derived from one Language into another, the derived Words are there turned and changed according the particular Genius of the Language into which they are transplanted" (Wotton, [1713] 1730: 57). De todos modos, Wotton no fue el primero en exponer tal razonamiento. En una carta escrita alrededor del año 1665 y que fue publicada por vez primera en 1684 con el título de Of Languages, and particularly of the Saxon tongue, Thomas Browne (1686: IV, 45) dice al comparar el vasco con las lenguas latinas: "but although in this brief Form [of the Lord's Prayer] we may find some commixture [Santifica, tentationeten, Gloria, puissança, and four more], yet the bulk of their Language seems more distinct, consisting of words of no affinity unto others, of numerals totally different, of differing Grammatical Rule". Poco tiempo después, en su Commentarius de 1691, Hiob Ludolf (1691: 442-443) diría en parecido sentido: "Si enim linguam alteri affinem dicere velimus, necesse est, non tantùm, ut ea contineat nonnulla alterius cujusdam linguae vocabula, sed etiam ut Grammaticae ratio maxima sui parte eadem sit, qualis convenientia cernitur in Orientalibus, Ebraea, Syriaca, Arabica \& Aethiopica: nec non in Italica, Hispanica \& Gallica Occidentalibus linguis, quae rectè afines inter se dicuntur'. El propio Ludolf (1702: preliminares) repetiría esta idea en un capítulo titulado "Dissertatio de origine, natura et usu Linguae Aethiopicae" de su Grammatica Aethiopica: "Lingua Aethiopica originem suam traxit ex Arabica, cujus filia censeri potest, sicuti ista Hebraeam pro matre agnoscit. Etenim Aethiopes nostri, cùm temporibus antiquissimis ex Arabia in Africam transfretarent, patriam illius temporis dialectum secum transtulerunt. Id clarè apparet non tantum ex copia vocum harmonicarum, quae ultra tertiam hujus linguae partem conficiunt, sed \& ex ipsa Grammatica, qua cum Arabica convenit. Nam, ut in Commentario diximus, eaedem penè sunt Conjugationes, illarumque significationes: eademque conjugandi ratio".

61 La versión inglesa de su discurso reza así: "But the Finnish, the Slavonian, and the Hungarian seem to be original Tongues, and to have no real Affinity with the Teutonic, or the Greek. Whether the Cantabric, and the antient Gaulish, (of which the British, the Irish, the Aremorican, and the Manks are but Dialects) be not so likewise I will not decide" (Wotton, [1713] 1730: 42-43). 
Sed Finnica, Slavonica, \& Hungarica videntur esse Originales nullamque realem affinitatem cum Teutonicâ aut Graecâ habere: Num Cantabrica \& vetus Gallica (cujus Britannica, Hibernica \& Aremorica sunt Dialecti) etiam sint originales, non decidam.

\subsubsection{Mathurin Veyssière de Lacroze}

\subsubsection{La disertación de Lacroze}

[Fuente: Chamberlayne, 1715: II, 125-142]

También el bretón Mathurin Veyssière de Lacroze ${ }^{62}$ hubo de tomar, como Urte, el camino del exilio por motivos religiosos. Su destino final sería Berlín, donde, en 1702, sería nombrado bibliotecario de la Königliche Bibliothek. Precisamente desde la capital prusiana, Lacroze remitiría su disertación el 16 de noviembre de 1714 a Chamberlayne, quien la publicó con el título de "Dissertatio de variis linguis". El discurso de Lacroze se centró fundamentalmente en el estudio de las lenguas orientales y del gótico. Es al hablar de las posibles conexiones entre gótico y fráncico y de los dialectos de este último cuando, incidentalmente, Lacroze (Chamberlayne, 1715: II, 141) escribe que también el euskara, según relata Oihenart en su Notitia utriusque Vasconiae, está dividido en varios dialectos: "Sic apud cantabros duplicem imo \& triplicem Dialectum observat Oihenart in Notitia Vasconiae”.

En realidad, Oihenart (1638: 71) distingue en esta obra cuatro dialectos:

62 Lacroze (Nantes 1661 - Berlín 1739) ingresó en la orden de los benedictinos en 1677, ocupando poco más tarde el puesto de bibliotecario en la abadía de Saint-Germain-des-Prés. El tiempo que Lacroze dedicaba a sus trabajos de investigación era, en opinión del padre prior, desproporcionado y le alejaba de sus auténticos deberes religiosos. Lacroze, sumamente descontento por las presiones de su superior, abandona en 1696 la abadía y marcha a París, donde se aloja en casa de un amigo protestante. En breve partirá como refugiado hacía Basilea donde consuma su apostasía y abraza la fe calvinista, recalando poco después en Berlín. De Lacroze se decía que era un políglota que conocía multitud de lenguas, aunque, evidentemente, el párrafo que a continuación reproducimos es una flagrante exageración de sus biógrafos (Levot, 1857: II, 83, nota): "Il parlait avec facilité l'anglais, l'espagnol, le portugais et l'italien; il parlait moins l'allemand, qu'il entendait. Il possédait d'ailleurs les langues savantes, le grec ancien et le vulgaire, l'hébreu, l'arabe, le syriaque, le cophte, l'arménien. Il avait appris en assez peu de temps le slavon, l'anglo-saxon et le basque. Il s'était beaucoup appliqué au chinois, dont il avait quelque teinture". A pesar de que Leibniz le rogó en infinidad de ocasiones que se dedicase al estudio del chino, Lacroze prefirió centrarse, sucesivamente, en las lenguas armena y copta, elaborando diccionarios de ambos idiomas -aunque sólo llegaría a publicarse, y además póstumamente, su Lexicon aegyptiaco-latinum-. En 1724, Lacroze publicaría una obra titulada Histoire du Christianisme des Indes en la que aparecería una observación que pudo haber sido revolucionaria en tanto en cuanto se llamaba la atención sobre la similitud entre el sánscrito y el persa: "J'ai remarqué plusieurs autres choses communes aux Indiens \& aux anciens Persans; entre autres un grand nombre de mots \& de noms semblables dans l'une \& dans l'autre Langue: mais j'ai jugé à propos de les obmettre pour éviter la prolixité. D’autres y pourront faire attention" (Lacroze, 1724: 439). El descubrimiento de los vínculos entre el sánscrito y otras diversas lenguas desembocaría en la revelación de la existencia de la familia lingüística indoeuropea y en el nacimiento de la lingüística comparada. Aunque ya desde finales del siglo XVI álgunos autores habían puesto de relieve las semejanzas entre el sánscrito y otras lenguas, sus observaciones bien no fueron publicadas hasta siglos después bien pasaron inadvertidas. Habría que esperar hasta el año 1786 para que William Jones (1788: I, 422-423) estableciese de forma indubitada la conexión entre el sánscrito, el latín y el griego, así como la posibilidad de extender esta ligazón a otras lenguas como el gótico, el gaélico y el persa. Produce cierto sentimiento de tristeza el pensar que, tras dedicar buena parte de su vida a las indagaciones lingüísticas más diversas, Lacroze dejase pasar de lado justamente el tema que podría haberle proporcionado renombre. Una vez verificadas las conexiones entre el sánscrito y el persa, y sabedor de los vínculos entre persa y alemán, sólo tenía que haber tirado un poquito más del hilo para haber sido él quien hubiese pasado a la historia como descubridor de la gran familia lingüística indoeuropea. 
Caeterum in superioribus, declinationum \& inflexionum regulis atque exemplis dialectum ferè Vascitanam secuti sumus, eam inquam quae illorum è Vasconibus Aquitanis, qui Vasci vulgò dicuntur, propria est; Ab hac nonnihil difert Navarrica, plusculum Vardulica, seu Ipuscuana \& Alavensis, omnium maximè Autrigonica seu Biscaina, quas hic sigillatim exponere, aut inter se conserre non est nostri instituti.

La división dialectal planteada por Oihenart en la Notitia de 1638 no es especialmente brillante, máxime si tenemos en cuenta que, unos años más tarde, publicaba una obra titulada Les proverbes basques recueillis par le sr. d'Oihenart plus les poesies basques du mesme auteur, en la que demostraba su profundo conocimiento de los dialectos vascos, especialmente de los del norte (Oihenart, 1657: II, 67-75) ${ }^{63}$.

\subsubsection{El dialecto berriense}

\subsection{Lacroze a Wilkins, Berlín, 04-09-1714}

[Fuente: Uhl, 1746: III, 244]

Pero volviendo a la Oratio Dominica de 1715, debemos hacer notar que Lacroze, pocos días antes de enviar su disertación a Chamberlayne, había mantenido relación epistolar con el colaborador de éste, David Wilkins. La lectura de dicha correspondencia nos muestra que Lacroze fue el responsable de que no se incluyese en la obra de Chamberlayne -a diferencia de lo que había ocurrido en anteriores recopilaciones- la versión del padrenuestro en un supuesto dialecto berriense:

nec satis intellexeram, cum nuper ad te scripsi, nondum inspecto orationum Dominicarum vestrarum catalogo, de quarum edendarum consilio utinam maturius certior factus essem. Porro, antequam finem faciam, aurem iterum tibi vello de tollenda inepta illa versione Berriensi. Nulla umquam vel fuit, vel erit Berriensis dialectus, nec puto, gens ulla est illius nominis in orbe terrarum. Scio Bituricensem provinciam Gallice appellari le Berri, sed illius provinciae homines Gallico sermone utuntur, etiam in pagis. Sed quid verbis opus est in re clara? Novum Testamentum lingua Cantabrorum sumtibus Ioannae Albretensis matris Henrici IV. regis Franciae, Rupellae editum fuit in octavo seculo XVI. Ei libro praefixus est titulus Testament Berri, quae vox Berri Cantabrice, quemadmodum et Coptice novum significat; nec unam hanc vocem Copticis similem habere Cantabros deprehendi ex eorem libris, quorum nonnullos habeo. Huius novi Testamenti in Bibliothecae Bodeleianae Catalogo, ubi exstat p. 198. colum. 2. titulus sic scribitur: Nov. Test. in lingua de Berria, in confinis Biscaiae. Nimirum haec vox Berri bono Hydio fraudi fuit, et post eum Mullero, qui pagina 37. editionis suae sylloges, Berriensem linguam et novum Testamentum Berriense aliquo loco exstare censuit, quae certe eadem est, quae supra hanc in eadem hacce pagina edita fuit, Cantabrica videlicet.

63 Oihenart incluyó en esta obra un apartado titulado "Neurtiz hautaco hiz bekanen adigarria", que comprendía un glosario de voces vascas seguidas de sus correspondientes francesas para, así, aclarar al lector el significado de las mismas. Como el propio Oihenart (1657: II, 67) dice al pie de su "explication des mots rares qui se rencontrent parmy ces Vers", la riqueza multidialectal del euskara "est cause de ce que plusiers mots anciens Basques, qui se sont conservez en chacune des ces Provinces, ne sont pas entendus en l'autre”. Por ello cada término vasco de su vocabulario va seguido de una letra inicial que identifica el dialecto o euskalki del que proviene ( $L$. labortano; $L$. Oc. labortano occidental; $B$. bajo-navarro; $S$. suletino; $S$. $M$. suletino meridional; y $N$. alto-navarro). 
El causante del yerro, como indica Lacroze en su carta, fue el orientalista Thomas Hyde, quien en su calidad de director adjunto de la Bodleian Library de Oxford, había editado el catálogo de sus libros. Al hablar en el mismo de la traducción al vasco del Nuevo Testamento (Testamentu Berria) por Leizarraga, Hyde (1674: 198) interpretó inadecuadamente el adjetivo berria (nuevo), describiendo de esta manera la obra de Leizarraga: "Nov. Test. in lingua de Berria, in confinis Biscaiae". Andreas Müller, buen amigo de Hyde, hizo - como dice Oroz (1980: 20, nota) - "de la necesidad virtud, buscando esa lengua y descubriendo el dialecto berriense", para incluirlo en su colección de padrenuestros de 1680. Posteriormente, haría lo propio Benjamin Motte en su Oratio Dominica de $1700^{64}$.

En realidad, hay en el centro de Francia una pequeña región denominada -hasta la revolución de 1789- Berry o Berri, con capital en Bourges. Sus habitantes hablan un patois, hoy prácticamente extinguido, que llaman berrichon, del cual incluso han llegado a publicarse diccionarios y estudios filológicos. La cuestión, pues, no era tanto el negar la existencia de un habla berriense o berrichonne, sino preguntarse, con Oroz (1980: 20, nota), «qué méritos tiene ese dilatado berriense para figurar en las colecciones».

\subsection{Wilkins a Lacroze, Amsterdam, 06-10-1714}

[Fuente: Uhl, 1742: I, 369]

Wilkins agradece a Lacroze su colaboración y le confirma, ya en las vísperas de su edición, la desaparición de la versión berriense de la obra de Chamberlayne:

Multum tibi debet Chamberlaynius noster pro orationibus dominicis, quas mihi communicare voluisti [...] Berriensem, ut vocatur in editis orationibus dominicis, omittam.

No creamos, sin embargo, que ello supuso la desaparición del berriense de las sucesivas colecciones del género, pues siguió incluyéndose en las mismas durante los siglos XVIII, XIX e, incluso, XX.

\section{Una carta de Jablonski a Lacroze acerca de la posible publicación de la Grammaire Cantabrique de Urte.}

\subsection{El texto de la carta}

[Fuente: Uhl, 1742: I, 165]

El joven orientalista Paul Ernst Jablonski ${ }^{65}$, envió el 3 de noviembre de 1716 desde Hannover una carta a Mathurin Veyssière de Lacroze en la que se hacía referencia a una gramáti- 
ca de la "lingua Biscayana". La misiva es, ciertamente, interesante, pues creemos que puede aportar alguna información inédita acerca de la Grammaire Cantabrique de Urte:

\begin{abstract}
Vicissim vero a te efflagitat, ut, quid de lingua Biscayana tibi constet, id secum communices, inprimis scire avet, sitne quaedam grammatica huius linguae a fratre Dusarratii Berolinensis bibliopolae, quem in Hispania vidit et cognovit, edita. Nomen huic viro est Haspergio.
\end{abstract}

Por aquellas fechas, y hasta donde alcanzan nuestras noticias, sólo se estaban escribiendo dos gramáticas vascas ${ }^{66}$ : la de Pierre d'Urte y la de Nicolas Fréret. Aunque -como a continuación veremos- parece claro que en la carta se hace referencia a la primera, trataremos también, siquiera sea sumariamente, la gramática de Fréret.

\title{
5.2. Nicolas Fréret: Essay d'une Grammaire de la Langue Basque (ca. 1714)
}

La gramática vasca manuscrita del historiador y lingüista Nicolas Fréret ${ }^{67}$, es poco más que la traducción al francés de los breves pero interesantes apuntes gramaticales que aparecen en la obra Notitia utriusque Vasconiae, escrita por Oihenart en $1638^{68}$. El manuscrito de Fréret, que acabaría llegando a las manos del eminente lingüista Wilhelm von Humboldt, ha permanecido inédito hasta su reciente publicación por Bernhard Hurch (2002: 81-110).

el copto, como consta en carta dirigida a Leibniz el 20-12-1715: "Il est à souhaiter que cette langue [le Cophte] devienne un peu connüe [...] J'y ai fait des decouvertes importantes, \& afin qu'elles ne perdissent point à ma mort, je les ai toutes enseignées au fils de Mr. Jablonski, qui est un jeune homme d'un esprit admirable. A l'heure qu'il est, il sçait mieux le Cophte que Mr. [David] Wilkins" (Ms. de la GWLB, LBr. 517 B1. 83-84).

66 Quizás podríamos añadir la obra de Joannes Etcheberri de Sara, Escuarazco hatsapenac Latin Ikhasteco (Urquijo, 1907: 203-377). Su primera versión fue escrita en 1712, pero su autor realizó posteriormente diversas correcciones y en 1728 fue presentada al Biltzar de Lapurdi con la intención -lamentablemente frustrada- de que dicha asamblea adelantase la cantidad de dinero necesaria para su publicación. Aunque en puridad se trate de una gramática del latín escrita en vasco, su carácter bilingüe permite, en cierto modo, hablar también de esta obra como de una gramática vasca. Ya dijo en su día Villasante (1979: 107) que "en realidad, más parece que quiere enseñar vasco que latín, pues a propósito de cualquier verbo o tiempo latino amontona cantidad de flexiones vascas".

67 Aunque inducido por su padre a estudiar leyes, los intereses científicos de Nicolas Fréret (París 1688 - París 1749) se decantarían bien pronto hacia la Historia y -aunque prima facie sólo como medio instrumental para el estudio de aquella- la Lingüística. En contacto con la Académie des Inscriptions et Belles-Lettres desde 1714, fue nombrado académico y secretario de la misma en 1716 y 1742, respectivamente. En 1714, Fréret escribió una memoria titulada "Histoire de l'origine des Français" en la que presentaba a los francos como originarios del sur de Germania y ancestros de los actuales franceses. Esta teoría fue considerada por alguno de sus enemigos como políticamente incorrecta, máxime en una época de grandes tensiones entre Francia y Alemania, y fue la principal causa de su encarcelamiento en La Bastilla - del que enseguida tendremos ocasión de hablar-. No debió ser pequeño el interés de Fréret en el estudio de la lengua vasca cuando, a falta de obras impresas, él mismo se encargaría de confeccionarse una gramática y un vocabulario de dicha lengua. Sin embargo, no parece que sus estudios en este campo le llevasen a otra conclusión que la de constatar la inexistencia de relaciones entre el vasco y el resto de las lenguas vivas. Sí consideraba, en cambio, que tal relación de parentesco existía con la extinta lengua íbera: "les Cantabres, et les peuples de l'extrémité occidentale des Pyrénées, ont conservé l'ancienne langue ibérienne, dont les Basques parlent encore aujourd'hui un dialecte" (Leclerc de Septchênes [1724] 1796: I, 254). En cierto sentido, podríamos considerar a Fréret como un precursor de la tesis vasco-iberista de Humboldt.

68 Concretamente, Fréret hace uso del cap. XIV -titulado "Singularia quaedam linguae Vasconicae déque vocabulorum Vasconicorum declinandi \& coniugandi ratione"- del libro I de la obra Notitia utriusque Vasconiae tum Ibericae tum Aquitanicae (Oihenart, 1638: 57-72). 
Aunque nadie hasta ahora había datado la gramática de Fréret, nosotros creemos que ésta hubo de ser redactada en el periodo de tiempo comprendido entre los años 1711 y 1714 . A finales de este último año, y por infundadas sospechas político-religiosas, las autoridades francesas dieron orden de detener a Fréret, así como de confiscarle todos sus papeles y trasladarle a La Bastilla, donde permaneció encarcelado entre el 26 de diciembre de 1714 y el 31 de marzo de 1715. Trabajador infatigable, Fréret trató de aprovechar su estancia en prisión para continuar con sus estudios lingüísticos. Para ello, solicitó ${ }^{69}$ a las autoridades que, de entre sus documentos confiscados, le devolviesen su gramática y su vocabulario ${ }^{70}$ vascos. Ésta fue la concreta petición de Fréret, según aparece reproducida por Delort (1829: II, 16):

Dans le pacquet intitulé Iberica, un vocabulaire et un essay de grammaire de la langue basque, et une dissertation sur le dieu Endovellicus; dans le pacquet intitulé Etymologica, plusieurs vocabulaires des langues orientales et septentrionales.

A la vista de las obras que Fréret utilizó en sus indagaciones acerca de la lengua vasca, parece claro que fue la obra de Eckhart, Historia Studii Etymologici, la que le sirvió de referencia para sus fuentes ${ }^{71}$. Ello nos permite datar aún con mayor concreción los manuscritos vascos de Fréret, ya que los mismos habrían de ser posteriores a 1711, año en el que Eckhart publicó su obra.

\subsection{Pierre d'Urte: Grammaire Cantabrique (ca. 1714)}

En la misiva de noviembre de 1716 más arriba reproducida, Jablonski le transmite a Lacroze el deseo que muestra «Haspergio» de saber si algún hermano del impresor berlinés Dusarrat había editado una gramática de la lengua vasca. Jablonski debe de estar refiriéndose, sin duda, a Heinrich Hasperg, diplomático al servicio del ducado de Wolfenbüttel. Leibniz era por aquel entonces director de la Herzog August Bibliothek de dicho ducado, y aprovechaba las estancias de Hasperg en los más diversos países europeos para encargarle la compra de libros para la biblioteca ducal.

Es la presencia de la figura de Hasperg en la carta que ahora estamos analizando, la que nos permite concluir que la gramática vasca de la que se está hablando debe ser la de Urte.

69 La solicitud la formuló Fréret el 16 de marzo de 1715 y fue satisfactoriamente respondida a los pocos días. En breve, Fréret sería puesto en libertad.

70 En cuanto al Vocabulaire basque, tiré de la traduction du nouveau test. par Leiçarraga, los editores de los manuscritos vascos de Humboldt no han considerado pertinente su publicación, ya que, en su opinión, las palabras vascas de dicho vocabulario "aunque las hubiera usado Humboldt, no tienen valor científico alguno" (Hurch, 2003: 84).

71 En dicha obra, Eckhart (1711: 171-172) dedica un breve capítulo a la "Lingua veteri Cantabrica". En el mismo, señala como únicas obras de referencia para el estudio de la lengua vasca las siguientes: el Testamentu Berria de Leizarraga (con el que Fréret elaboró su vocabulario vasco "tiré de la traduction du nouveau test. par Leiçarraga"), la ya nombrada Notitia de Oihenart (como hemos dicho, fuente del Essay de Grammaire de Fréret) y el Deo Endovellico de Reinesius (1637). Con respecto a esta última obra, Fréret (Leclerc de Septchênes [1714] 1796: XVIII, 285-298) escribiría en 1714 una disertación titulada "Recherches sur le dieu Endovellicus, et sur quelques autres antiquités ibériques", en la que ya manifestaba su opinión acerca del vasco como reducto de la lengua íbera. Nosotros nos inclinamos a pensar que es muy posible que también en 1714 hubieran sido escritos su gramática y su vocabulario vascos. 
Hasperg estuvo residiendo una temporada en Londres y, durante su estancia en la capital británica, era él quien se encargaba de remitirle a Leibniz las cartas de Chamberlayne. En misiva remitida a Leibniz el 27 de febrero de $1714^{72}$, Chamberlayne, además de ofrecerse para mediar entre él y Newton, hace referencia a otra carta que le ha enviado recientemente vía Hasperg, y que no es sino la de 18 de febrero de $1714^{73}$. Esta última carta es precisamente aquella en la que, como ya vimos, Chamberlayne le hablaba a Leibniz de que tenía a Urte «employed in compiling a Grammar of this Language very copiously». Parece, pues, evidente que Hasperg supo de la existencia de la gramática de Pierre d'Urte por el contenido de esta misiva de Chamberlayne.

En cuanto al «Berolinensis bibliopolae, quem in Hispania vidit et cognovit» que cita, es seguro que Jablonski debe de estar hablando de Arnaud Dusarrat, librero y editor afincado en Berlín. No sabemos si Arnaud llegó a vivir exactamente en «Hispania», pero sí muy cerca de su frontera, en Baiona (Bayonne), de donde era natural. Como Urte y Lacroze, también Arnaud Dusarrat tuvo que emigrar de Francia a raíz de la Revocación del edicto de Nantes, y así aparece citado por Béringuier (1888: 12) $)^{74}$ en el rol de refugiados en La Haya con fecha de 31 de diciembre de 1699. Tras una breve estancia en aquella ciudad, Arnaud partió hacia Berlín, donde, ya en 1702, aparecen libros por él editados.

No obstante, Jablonski habla más precisamente de un «fratre Dusarratii»; y resulta complicado averiguar quién pudo ser concretamente este hermano de Arnaud, de entre los diez hijos que, como nos refiere Godinot (1965: 123), tuvo el librero bayonés Menaut Dusarrat. El más conocido, al menos en el ámbito de la vascología, fue Pierre Dusarrat, continuador del negocio de su padre -y de su abuelo, Claude Couronneau- en la capital labortana. Pierre Dusarrat trascendió su condición de mero vendedor de libros para, como tantos otros colegas suyos, pasar también a editarlos ${ }^{75}$. Pero dado que Pierre falleció en 1708, parece claro que otro debe de ser el hermano de Arnaud que tratamos en vano de identificar ${ }^{76}$. En cualquier

72 Vid. sup. $\S 3.4$.

73 Vid. sup. $\$ 3.3$.

74 «Le Sr Arnauld Du Sarrat, Bayonne, Libraire, sa femme et un enfant».

75 Tal sería el caso, en 1693, de la cuarta edición de la obra religiosa en lengua vasca, Dotrina Christiana, del padre Esteve Materre. En esta edición se le puso el título de Bouqueta lore divinoena y, en la misma, aparece el nombre de «Piares Dussarrat» como «liburu eguilea»-o, siguiendo la literal traducción de Vinson (1898: II, 521522), «faiseur de livres»-.

76 Según los datos de una encuesta oficial realizada en 1701 sobre la situación de los impresores y libreros en Baiona, Pierre Dusarrat, tras un largo periodo de aprendizaje en imprentas de Burdeos, París y diversas localidades españolas e italianas, instalaría definitivamente su negocio en la capital labortana, siguiendo así la tradición familiar. Allí habría trabajado ayudado por «deux apprentis, ses propes frères, qu'il instruisait dans la profession», sin que sepamos «que sont devenus ses jeunes frères, ses apprentis» (Godinot, 1965: 124). Además del ya referido Arnaud Dusarrat, Béringuier (1888: 14) nos habla de otro librero de Baiona, refugiado en Colonia en 1699, y que respondía al nombre de Jean Dusarrat. Éste abriría en aquella ciudad una librería que, años más tarde, trasladaría a Estocolmo, ciudad en la que falleció en 1723 y en la que fue conocido como Johan du Sarrat. De todos modos, tanto Jean como Arnaud ya constan como refugiados en Alemania en 1699, por lo que difícilmente pueden ser los hermanos y ayudantes de Pierre nombrados en la encuesta-officielle, recordemos-de 1701. Por otro lado, y hablando de la inexistencia en Brandenburgo, a finales del s. XVII, de impresores y libreros que se ocupasen de las obras escritas en lengua francesa -en definitiva la lengua culta en la Germania de aquel entonces-, Reyer (1852: 184) comenta que tal estado de cosas cambió con la llegada de los refugiados, nombrando entre ellos a los hermanos Estienne y Naudé Dussarrat, que establecieron su negocio en Berlín. Reyer no refiere la fecha exacta del establecimiento de estos nuevos hermanos Dusarrat en Berlín, por lo que es posible que llegasen allí tras la encuesta de 1701. De 
caso, creemos que lo trascendente en este punto es que la referencia a un concreto librero o editor apellidado Dusarrat - con independencia de cuál fuera, en definitiva, su nombre de pila- es suficientemente indicativa de la seriedad de la noticia de Hasperg transmitida por Jablonski a Lacroze.

Casi todos los críticos que se han acercado al estudio de la Grammaire Cantabrique de Urte han aducido en su contra -entre otras consideraciones- el enorme desorden en el que se hallan dispuestos sus contenidos ${ }^{77}$. Por ello, un autor tan competente en la materia como Oiharçabal (1989: 70) ha llegado a manifestar que el manuscrito que conocemos «ne correspond pas à une version vraiment définitive». Sin embargo, y a la vista del contenido de la carta de Jablonski, tal vez habría que reconsiderar esta postura y empezar a pensar que, como en su día ya planteó Thomas $^{78}$, posiblemente la obra estuviese ya presta para su impresión. Sabemos que en el manuscrito original de Urte los folios no estaban numerados; es así posible que, como apuntó Webster ${ }^{79}$, el tantas veces invocado desorden pudiera deberse simplemente al hecho de que alguna mano inexperta -0 incluso, sucesivamente, varias- los enmarañase. Por otro lado, la gramática francesa de Claude Mauger, modelo de la de Urte, no es precisamente un ejemplo de orden y sistema.

No nos parece descabellada, en definitiva, la posibilidad de que en aquellos años un editor-vasco además de Lapurdi, como Urte- pudiera plantearse seriamente la publicación de la Grammaire Cantabrique. De cualquier manera, finalmente no fue así, y al genial jesuita Manuel de Larramendi le cupo el honor, en 1729, de publicar la primera gramática vasca con el título de El imposible vencido: Arte de la Lengua Bascongada.

\section{Conclusiones}

Entre finales del s. XVII y principios del s. XVIII trabajaba en Europa todo un coro de eruditos especialmente interesados en descubrir los posibles vínculos entre las distintas lenguas del orbe. No debe, por ello, extrañar que algunos de estos lingüistas se afanaran en tratar de desentrañar los arcanos de la vieja lengua vasca, que de manera tan notable difería

cualquier manera, preferimos dejar en este punto la cuestión, pues ya hemos nombrado a cinco diferentes hermanos Dusarrat, todos ellos libreros, sin que realmente nuestras investigaciones nos hayan conducido a conclusión válida alguna.

77 El propio editor de la gramática, Webster (1900: iii), tuvo que tratar de reordenar los folios del manuscrito debido al evidente desbarajuste existente: «Nous avons fait de notre mieux pour les classer comme elles auraient dû l'être, et nous croyons avoir réussi, autant que le manque complet de méthode de Pierre d'Urte nous l'a permis». También se expresa en parecido sentido Michelena ([1960] 2001: 83), quien dice que «los materiales están presentados en un desorden caótico».

78 «This is a folio volume of 540 pages. It is written in a careful and legible hand on both sides of the leaf, it contains few erasures and corrections and (unlike the other MSS.) is apparently not a first, but a final copy ready for the Press» (Thomas, 1894: ix). Urte llega incluso a coronar su obra con la cita bíblica «Soli Deo honor et Gloria in saecula saeculorum. Amen».

79 Es un hecho cierto que en su origen las hojas del manuscrito no estaban numeradas, pero lo que ignoramos es si la noticia que Webster (1900: iii) ofrece a continuación es también un hecho o una simple conjetura: «les feuillets manuscrits n'étaient pas numerotés. A une époque indeterminée, en les unissant pour les donner au relieur, le bibliothécaire de Shirburn Castle les laissa tomber: il s'empressa de les ramasser, de les arranger, de les numéroter, aussi bien que pouvait le faire quelqu'un qui ne savait pas le premier mot de la langue Basque». El propio Webster, como acabamos de ver, tuvo que reordenar a su vez los folios. Pero, además, Webster (1900: iv) no pudo utilizar el original, sino una copia manuscrita del mismo: «nous ne l'avons jamais vu [le Ms. original]». 
del resto de los idiomas europeos. De algunos de estos precursores de la vascología hemos hablado en este artículo, pero no fueron los únicos, desde luego.

Todos ellos tropezaron con una dificultad prácticamente insalvable: la casi absoluta inexistencia de materiales gramaticales y lexicográficos impresos relativos a la lengua vasca. En efecto, en la época en la que Urte escribió su Grammaire Cantabrique, aún no se había editado gramática vasca alguna; tan sólo podríamos hacer referencia en este campo-siempre, recordemos, haciendo abstracción de las obras manuscritas- a la «Spece de Grammaire» que incluyó Voltoire ( $c a$. 1620: 1-40) en su obra L'Interprect ${ }^{80}$, y al capítulo que Oihenart (1638: 57-72) dedicó a la gramática vasca en la Notitia utriusque Vasconiae ${ }^{81}$. La situación no era mucho mejor en el ámbito de la lexicografía vasca, pues por aquel entonces únicamente se habían impreso los siguientes repertorios lexicográficos: el del humanista siciliano Lucio Marineo Siculo (1530: xxix), quien había insertado un vocabulario de poco más de 50 palabras vascas en su obra De las cosas memorables de España ${ }^{82}$; el también breve (alrededor de 120 voces) «Vocabulorum aliquot Cantabricorum» de Bonaventura Vulcanius (1597: 92-96), cuyas fuentes habían sido la obra de Marineo Siculo y el Testamentu Berria de Leizarraga $^{83}$; los poco más de 130 vocablos vascos -tomados de las obras de Marineo Siculo y de Vulcanius, además de una decena de gasconismos- que aparecían en los dos volúmenes del Thesaurus Polyglottus de Hyeronimo Megiser (1603); y, finalmente, el ya más voluminoso (alrededor de 1.000 entradas) «Dictionaire alphabetique» incluido por Voltoire (ca. 1620: 41131) en su ya referida obra L'Interprect.

En no pocas ocasiones, la reseñada ausencia de gramáticas y diccionarios vascos obligaba a los investigadores a realizar ímprobos esfuerzos para procurarse tales materiales. Así, y sin ánimo de ser exhaustivos, podemos hablar de casos como el del sueco Johan Gabriel Sparwenfeld, quien en su intento de confrontar el euskara con el gaélico irlandés y con el georgiano, hubo de solicitar del bibliotecario francés Étienne Baluze un listado de palabras vascas con el que acabaría elaborando su breve vocabulario latín-vasco-gaélico (Specimen linguarum Cantabrica/Iberica et Irlandica/Hibernica). Edward Lhuyd, por su parte, tuvo que recurrir al Nuevo Testamento (Testamentu Berria) de Leizarraga para confeccionar su diccionario manuscrito latín-inglés-vasco (Bascuenza lingua sive Cantabria). También Fréret utilizó el mismo sistema que Lhuyd para redactar su Vocabulaire basque, tiré de la traduction du nouveau test [ament] par Leiçarraga. Leibniz, por último, pidió insistentemente -y en vano, si exceptuamos la fundamental colaboración de Chamberlayne- noticias sobre la lengua vasca a más de una decena de sus corresponsales.

\footnotetext{
80 L'Interprect no era sino un mero manual de conversación de aquellos que tan en boga estuvieron en Europa entre los siglos XVI y XVII, y conviene apuntar que este tipo de obras tienen una finalidad prática inmediata, la de la comunicación oral entre personas de distintas lenguas, que excluye la inclusión de complejas formulaciones gramaticales. La obra de Voltoire - con toda probabilidad un seudónimo-conoció múltiples reediciones, casi siempre con distinto título y con variaciones en el contenido.

81 Vid. sup. § 5.3. En 1656 se publicaría una segunda edición de la Notitia de Oihenart.

82 Hubo también una versión en latín de la obra con el título De rebus Hispaniae memorabilibus, en la que también aparece el pequeño vocbulario vasco (Marineo Siculo, 1533: xxi). Vocabulario que, años más tarde, sería transcrito en sus obras por Paulo Merula (1605: 302-303) y por Pieter van der Aa (1707a: I, 41 y 1707b: I, 108-109). 83 Caspar Waser (1610: 135-136) reproduciría el «Vocabulorum» de Vulcanius en su particular reedición del Mithridates de Conrad Gesner.
} 
Este estado de cosas pudo haber cambiado radicalmente si el encargo que Chamberlayne realizase a Urte hubiese llegado a buen puerto, pero, desafortunadamente, su gramática no fue finalmente publicada hasta el año $1900 \mathrm{y}$, en cuanto a su diccionario, que ni siquiera pudo acabar, hubo de esperar hasta el año 1989 para ser editado.

La tardía publicación de las obras de Urte, unida a la circunstancia de su ubicación en la poco menos que inaccesible biblioteca privada del conde de Macclesfield, motivó que ni su gramática ni, menos aún, su diccionario pudiesen ejercer apenas influencia alguna entre los gramáticos y los lexicógrafos vascos posteriores. Amén de la magnífica edición de Urkizu, los términos del diccionario de Urte han sido recogidos en el Diccionario General Vasco (Orotariko Euskal Hiztegia) que iniciara Michelena y continuase Sarasola. La Grammaire Cantabrique, sin embargo, aún está a la espera de una edición crítica ${ }^{84}$. Si se materializan las intenciones del profesor Ricardo Gómez, es muy posible que ello tenga lugar en el ámbito de los Monumenta Linguae Vasconum, ambicioso proyecto de un grupo de expertos de la Universidad del País Vasco que, bajo la dirección de Joseba A. Lakarra, se propone, entre otras cuestiones no menos relevantes, la edición sistemática y crítica de las gramáticas vascas antiguas. Cabe esperar, en cualquier caso, que los vascólogos, presentes y futuros, profundizen en el estudio de las trascendentales obras de Pierre d'Urte ${ }^{85}$, tarea en la cual, este artículo, no hace más que aportar un pequeño granito de arena.

\section{Referencias bibliográficas}

[Aa, P. van der] (1707a): Beschryving van Spanjen en Portugal (2 vols.). Leiden, Pieter van der Aa. [Aa, P. van der] [seudónimo Juan Álvarez de Colmenar] (1707b): Les Delices de l'Espagne et du Portugal (5 vols.). Leiden, Pierre Vander Aa.

Allen, W. et alii (1898): Two Hundred Years: The History of the Society of Christian Knowledge, 1698-1898. London / New York, S.P.C.K.

Allières, J. (1985): «Statut et limites du polymorphisme morphologique: le verbe dans la grammaire cantabrique basque de Pierre d'Urte (1712): (1ère partie)», Anejos de Veleia - Series Maior, 1 2, págs. 899-919.

Allières, J. (1991): «Statut et limites du polymorphisme morphologique: le verbe dans la grammaire cantabrique basque de Pierre d'Urte (1712): Seconde partie (les auxiliares)», Anejos del ASJU, 14, págs. 767-812.

[Anónimo] (1693): Linguae Romanae Dictionarium luculentum novum: A new Dictionary, in five Alphabets. Cambridge, W. Rawlins [etc.].

Arens, H. (1975): La Lingüística. Sus textos y su evolución desde la antigüedad hasta nuestros días (2 vols.). Madrid, Gredos. Es traducción de la $2^{\mathrm{a}}$ ed. (1969) de la obra Sprachwissenschaft. Der Gang ihrer Entwicklung von der Antike bis zur Gegenwart.

Azkue, R. (1928): «Manuscritos vascos en Inglaterra», Euskera, 9, págs. 221-224.

84 Sin que esta afirmación implique, desde luego, que nos olvidemos de los importantes, aunque parciales, trabajos de autores como, por ejemplo, Allières (1985 y 1991) o Lakarra (1994).

85 Debemos resaltar la importancia que para ello supone el hecho de que los manuscritos originales de Urte se encuentren ahora en una biblioteca pública vasca - la de la Fundación Sancho el Sabio-, que además ya los ha digitalizado y puesto a disposición del público en internet (http://memoriadigitalvasca.es/), pues recordemos que ni Webster ni Urkizu, editores respectivamente de la gramática y el diccionario de Urte, tuvieron acceso a los mismos. 
Béringuier, R. (1888): Die Colonieliste von 1699: Rôle général des françois refugiez dans les estats de sa sérénité electorale de Brandenbourg, comme ils se sont trouvez au 31. décembre 1699. Berlin: E. S. Mittler.

Bilbao, G. (2008): «Claude Maugerren eskuliburua Urteren eredu», Anejos del ASJU, 51, págs. 129-152.

Bodemann, E. (1889): Der Briefwechsel des Gottfried Wilhelm Leibniz in der Königlichen öffentlichen Bibliothek zu Hannover. Hannover, Hahn.

Bonaparte, L. L. (1884): «Lord Macclesfield's Basque Mss. A letter from Prince L. L. Bonaparte to Mr. J. Rhys», The Academy, 26, págs. 306-307.

Bonaparte, L. L. (1885): «Descubrimiento de manuscritos bascos en Inglaterra: Manuscritos bascos de Lord Macclesfield», Euskal-Erria, 12, págs. 87-90.

Bonfante, G. (1953-1954): «Ideas on the kinship of the European languages from 1200 to $1800 »$, Cahiers d'histoire mondiale, 1, págs. 679-699.

Browne, T. (1686): The Works of Sir Thomas Brown (4 partes en 1 vol.). London, T. Basset [etc.].

Bruzen de la Martinière, A. A. (1726-1739): Le Grand Dictionnaire géographique et critique (9 ts. en 10 vols.). La Haye, P. Gosse [etc.].

Bullet, J. B. (1754-1760): Mémoires sur la langue celtique (3 vols.). Besançon, C. J. Daclin.

César, C. J. [ca. 50 a.C.] (1574): C. Julii Caesaris de bello gallico commentarii VII. A. Hircii de eodem liber octavus. Lugduni, B. Vincentium.

Chamberlayne, J. (1715): Oratio dominica in diversas omnium fere gentium linguas versa et propiis cujusque linguae characteribus expressa, una cum dissertationibus nonnullis de linguarum origine, variisque ipsarum permutationibus (2 partes en 1 vol.). Amstelodami, G. y D. Goerei.

Chamberlayne, J. (1718): Magnae Britanniae Notitia: or, The Present State of Great-Britain (2 partes en 1 vol.). London, T. Goodwin [etc.].

Couturat, L. (1903): Opuscules et fragments inédits de Leibniz. Paris, F. Alcan.

Davillé, L. (1909): Leibniz historien: Essai sur l'activité et la méthode historiques de Leibniz. Paris, F. Alcan.

Delort, J. (1829): Histoire de la détention des philosophes et des gens de lettres à la Bastille et à Vincennes (3 vols.) Paris, F. Didot.

Des Maizeaux, P. (1740): Recueil de diverses pièces sur la philosophie, la religion naturelle, l'histoire, les mathématiques, etc., par Messieurs Leibniz, Clarke, Newton (2 vols.). Amsterdam, F. Changuion. Es $2^{\mathrm{a}}$ ed. (la $1^{\mathrm{a}}$ es de 1720 ).

Dodgson, E. S. (1902): «Pierre d'Urte and the Bask Language», The American Journal of Philology, 23, págs. 151-184.

Dutens, L. (1768): Gothofredi Guillelmi Leibnitii, Opera omnia, nunc primum collecta (6 vols.). Genevae, fratres de Tournes.

Eckhart, J. G. (1711): Historia studii etymologici linguae germanicae. Hannoverae, N. Foersterum.

Edwards, E. (1864): Libraries and Founders of Libraries. London, Trübner.

Etcheberri [de Sara], J. (ca. 1712): Escuarazco hatsapenac Latin ikhasteco. Ms. editado en Urquijo 1907, págs. 203-377.

Etxegoien, J. C. [seudónimo Xamar] (2006): Euskara Jendea: Gure hizkuntzaren historia, gure historiaren hizkuntza. Iruñea, Pamiela.

Fréret, N. (ca. 1714): Essay d'une grammaire de la Langue Basque. Ms. editado en Hurch 2002, págs. 81-110.

Gesner, C. (1555): Mithridates. De differentiis linguarum tum veterum tum quae hodie apud diversas nationes in toto orbe terrarum in usu sunt. Tiguri (Zurich), Froschoverus.

Godinot, R. (1965): «Contribution à une Histoire de l'Imprimerie et de la Librairie à Bayonne», Bulletin de la Societé des Sciences et Arts de Bayonne, 107, págs. 119-132. 
Gómez, R. (2008): «Euskal gramatikagintza zaharraren historia laburra: XVII-XVIII. mendeak», Anejos del ASJU, 51, págs. 329-349.

Haramburu, J. (1635): Debocino escuarra, mirailla eta oracinoteguia. Bordelen, P. de la Court.

Hurch, B. (2002): Die baskischen Materialien aus dem Nachlass Wilhelm von Humboldts. Paderborn, F. Schöningh.

Hurch, B. (2003): «El programa de recopilación vascológica de Wilhelm von Humboldt», RIEV, $48-1$, págs. 73-90.

Hyde, T. (1674): Catalogus impressorum librorum Bibliothecae Bodleianae in Academia Oxoniensi. Oxonii [Oxford], E theatro Sheldoniano.

Jones, W. (1788): «The Third Anniversary Discourse, Delivered 2 February, 1786», Asiatick Researches, 1, págs. 415-431.

Lakarra, J. A. (1994a): «Euskal hiztegigintzaren historiarako, I: Harrieten Gramatikako Hiztegiak (1741)», ASJU, 28 - 1, págs. 1-178.

Lakarra, J. A. (1994b): «Euskal hiztegigintzaren historiarako, II: Gogoetak Urteren hiztegigintzaz», ASJU, 28 - 3, págs. 871-884.

Lakarra, J. A. (1994c): «Euskal hiztegigintzaren historiarako, III: Urteren Gramatikako hiztegia», ASJU, 28 - 3, págs. 885-914.

Lakarra, J. A. (1996): «Lexiko berrikuntza euskal hiztegigintza zaharrean: zenbait ikergai», Uztaro, 19 , págs. $20-22$.

Lakarra, J. A. (2001): «Práctica lexicográfica y teoría lingüística en el País Vasco (siglos XVIIXVIII)». En Maniqueira, Marina et alii (eds.): Actas del II Congreso Internacional de la Sociedad Española de Historiografía Lingüistica (León 1999), Madrid, Arco Libros, págs. 603-621.

Larramendi, M. (1729): El imposible vencido: Arte de la Lengua Bascongada. Salamanca, A. J. Villagordo.

Lastanosa, V. J. (1645): Museo de las medallas desconocidas españolas. Huesca, I. Nogues.

Leclerc de Septchênes (1796): Oeuvres complètes de Fréret (20 vols.). Paris, Dandré.

Leibniz, G. W. (1710): «Brevis designatio meditationum de Originibus Gentium, ductis potissimum ex indicio linguarum», Miscellanea Berolinensia ad incrementum scientiarium, 1, págs. 1-16.

Leibniz, G. W. [1714] (1715): «De variis linguis«. En Chamberlayne 1715, II, págs. 22-30.

Leibniz, G. W. [ca. 1711] (1717): Illustris viri Godofr. Guilielmi Leibnitii Collectanea Etymologica, illustrationi linguarum, veteris celticae, germanicae, gallicae, aliarumque inservientia (ed. de J. G. Eckhart; 2 partes en 1 vol.). Hanoverae, N. Foerster.

Leizarraga, J. (1571): Iesus Christ Gure Iaunaren Testamentu Berria. Rochella, P. Hautin.

Levot, P. (1852-1857): Biographie bretonne (2 vols.), Vannes / Paris, Cauderan [etc.].

Lhuyd, E. (ca. 1703): Bascuenza Lingua sive Cantabria. Ms. TCD [Trinity College of Dublin] 1320.

Lhuyd, E. (1707): Archaeologia Britannica, giving some account of the Languages, Histories and Customs of the Original Inhabitants of Great Britain. Oxford, Theater.

Littleton, A. (1678): Linguae Latinae liber Dictionarius quadripartitus: A Latin dictionary in four parts. London, T. Basset [etc.].

Ludolf, H. (1691): Jobi Ludolfi, alias Leutholf dicti, ad suam Historiam aethiopicam antehac editam commentarius. Francofurti ad Moenum, J. D. Zunneri [etc.].

Ludolf, H. (1702): Grammatica Aethiopica. Francofurti ad Moenum, J. D. Zunnerum [etc.].

Marineo Siculo, L. (1530): De las cosas memorables de España. Alcalá de Henares, M. Eguía.

Marineo Siculo, L. (1533): De rebus Hispaniae memorabilibus. Compluti (Alcalá de Henares), M. Eguía.

Mauger, C. (1653): The True Advancement of the French Tongue. London, T. Roycroft [etc.].

Mauger, C. (1684): Grammaire Francoise de Claude Mauger. Londres, R. B.

McKendry, E. (1997): «J. G. Sparwenfeld's contribution to Irish and Celtic material in Sweden», Zeitschrift für celtische Philologie, 49-50, págs. 516-531. 
Megiser, H. (1603): Thesaurus polyglottus vel dictionarium multilingue ex quadragentis circiter linguis, dialectis, idiomatibus et idiotismis constans (2 vols.). Francofurti ad Moenum, sumptibus auctoris.

Merula, P. (1605): Cosmographiae generalis libri tres: item Geographiae particularis libri quatuor, quibus Europa in genere, speciatim Hispania, Gallia, Italia, describintur. Amsterdam / Leiden, C. Nicolai [etc.].

Michelena, L. e I. Sarasola (1987-2005): Diccionario General Vasco - Orotariko Euskal Hiztegia (16 vols.), Bilbao, Euskaltzaindia [etc.].

Michelena, L. (2001): Historia de la Literatura Vasca. Donostia, Erein. Es $3^{\text {a }}$ ed. (la $1^{\text {a }}$ es de 1960).

Micoleta, R. de (1653): Modo breue de aprender la lengua vizcayna, Ms. editado en Zelaieta 1988, págs. 140-214.

Motte, B. (1700): Oratio Dominica (Polyglottos, Polymorphos) Nimirum, plus centum linguis, versionibus, aut characteribus reddita et expressa. Londini, D. Browne [etc.].

Müller, A. [seudónimo Lüdekenius] (1680): Oratio orationum s. s. Orationis Dominicae versiones praeter authenticam fere centum. Berolini, ex officina Rungiana.

Nicolson, W. [1713] (1715): «De universis totius orbis linguis». En Chamberlayne 1715, II, págs. $1-21$.

Nicolson, W. (1724): The Irish Historical Library. Dublin, A. Rhames [etc.].

Oihenart, A. (1638): Notitia utriusque Vasconiae tum Ibericae tum Aquitanicae. Parisiis, S. Cramoisy.

Oihenart, A. (1657): Les proverbes basques recueillis par le sr. d'Oihenart plus les poesies basques du mesme auteur (2 ts. en 1 vol.). Paris, [s.n.].

Oroz, F. J. (1980): «Vicisitudes de un Padrenuestro en vasco en el siglo XVII», ASJU, 14, págs. 3-23.

Oyharçabal, B. (1989): «Les travaux de grammaire basque avant Larramendi (1729)», ASJU, 23 - 1, págs. 68-72.

Pastor, S. (2001): «En busca de la lengua original: la teoría del vasco primitivo en Julio Cejador», ELUA, 15, págs. 149-176.

Reinesius, T. (1637): De Deo Endovellico cujus memoria nullibi veterum monumentorum praeterea quam in inscriptionibus antiquis in Villa Vizosa Lusitaniae repertis extat, commentatio parergica. Altenburgi, O. Michaelem.

Reyer, C. (1852): Geschichte der französischen Kolonie in Preussen. Berlin, F. Schneider [etc.].

Rhys, J. (1884): «The Earl of Macclesfield‘s Basque mss», The Academy, 26, págs. 168-169.

Rhys, J. (1885): «Descubrimiento de manuscritos bascos en Inglaterra: Manuscritos bascos del Conde de Macclesfield», Euskal-Erria, 12, págs. 84-87.

Robins, R. H. (2000): Breve historia de la lingüistica, Madrid: Cátedra. Es traducción de la $4^{\mathrm{a}}$ ed. (1997) de la obra A Short History of Linguistics.

Sparwenfeld, J. G. (ca. 1688): Specimen linguarum Cantabrica/Iberica et Irlandica/Hibernica. Ms. editado en McKendry 1997, págs. 521-523.

Thomas, L. (1894): The Earliest translation of the Old Testament into the Basque language (a fragment) by Pierre d'Urte of St. Jean de Luz, circ. 1700; edited from a Ms. in the Library of Shirburn Castle. Oxford, Clarendon Press.

Uhl, J. L. (1742-1746): Thesauri epistolici Lacroziani (3 vols.). Lipsiae, I. F. Gleditschii.

Urgell, B. (1997): «Estudios en torno a la historia de la lexicografía vasca», ASJU, 31 - 2, págs. 643-685.

Urkizu, P. (1988): «Pierre d'Urteren Hiztegia». En Lakarra, Joseba A. (ed.): Hiztegiak eta Testuak. Bilbo, EHU-UPV, págs. 75-94.

Urkizu, P. (1989): Pierre d'Urteren Hiztegia, Londres 1715 (2 vols.). Donostia, Deustuko Unibersitatea [etc.].

Urquijo, J. de (1905): «Los precursores de Azkue», Euskal-Erria, 53 - 2, págs. 285-286. 
Urquijo, J. de (1907): Obras vascongadas del doctor labortano Joannes de Etcheberri (1712). Paris, P. Geuthner.

Urte, P. d' (ca. 1714): Grammaire Cantabrique Basque. Ms. editado en Webster 1900.

Urte, P. d' (ca. 1715): Biblia Saindua. Ms. editado en Thomas 1894.

Urte, P. d' (ca. 1715): Dictionarium Latino-Cantabricum. Ms. editado en Urkizu 1989.

Veyssière de Lacroze, M. [1714] (1715): «De variis linguis«. En Chamberlayne 1715, II, págs. 125-142.

Veyssière de Lacroze, M. (1724): Histoire du Christianisme des Indes, La Haye, Freres Vaillant [etc.].

Villasante, L. (1979): Historia de la literatura vasca. [Oñati], Aránzazu. Es $2^{\mathrm{a}}$ ed. (la $1^{\mathrm{a}}$ es de 1961).

Vinson, J. (1891-1898): Essai d'une Bibliographie de la Langue Basque (2 vols.). Paris, J. Maisonneuve.

Vinson, J. (1893a): «Les manuscrits basques de Pierre d'Urte, de Saint Jean de Luz (vers. 1700)», $R L P h C, 26$, págs. 255-269.

Vinson, J. y A. Clark (1893b): «Vocabulaires basques de Pierre d'Urte [1 $1^{\mathrm{a}}$ parte]», $R L P h C, 26$, págs. 312-332.

Vinson, J. y A. Clark (1894): «Vocabulaires basques de Pierre d’Urte [2ª parte]», $R L P h C, 27$, págs. 28-48.

Vinson, J. (1897): «Notes de bibliographie basque: Pierre D'Urte, de Saint-Jean-de-Luz», $R L P h C$, 30, págs. 221-229.

Vinson, J. (1901): «Grammaire cantabrique basque, par Pierre d'Urte», RLPhC, 34, págs. 200-216 y 294-300.

Voltoire (ca. 1620): L'Interprect ou Traduction du François, Espagnol \& Basque. Lyon, A. Rouyer.

[Voltoire] (1642): Tresora Hirour Lenguaietaqua, Francesa, Espagnola, eta Hasquara. Bayona: F. Bourdot.

Vulcanius, B. (1597): De Literis et Lingua Getarum, sive Gothorum. Lugduni Batavorum (Leiden), Officina Plantiniana.

Waser, C. (1610): Mithridates Gesneri, exprimens differentias linguarum, tum veterum, tum quae hodie, per totum terrarum orbem, in usu sunt. Caspar Waserus recensuit et libello commentario illustravit. Editio altera. Tiguri (Zurich), Wolphianis.

Webster, W. (1893): «Nuevo tesoro del vascuence: Manuscritos labortanos de Pedro de Urte», Euskal-Erria, 29 - 2, págs. 65-68.

Webster, W. (1895): Le Dictionnaire Latin-Basque de Pierre d'Urte. Bayonne: A. Lamaignère. Separata del Bulletin de la Société des Sciences et Arts de Bayonne, 1895, págs. 541-564.

Webster, W. (1900): Grammaire Cantabrique Basque faite par Pierre D'Urte, 1712: manuscrit de la Bibliothèque du Comte Macclesfield. Bagnères de Bigorre, D. Bèrot. Separata del Bulletin de la Société Ramond, 1896-1900.

Wise, F. (1758): Some enquiries concerning the first inhabitants, language, religion, learning and letters of Europe. Oxford, J. Fletcher [etc.].

Wotton, W. [1713] (1715): «De confusione linguarum, exstructoribus Turris Babylonicae a Deo inflicta». En Chamberlayne 1715, II, págs. 37-75.

Wotton, W. [1713] (1730): A discourse concerning the confusion of languages at Babel. London, S. Austen [etc.].

Zelaieta, A. (1988): «Rafael Micoleta Çamudio: Modo breu de aprender la lengua vizcayna. Bilbao 1653», Hezkuntza eta Literatura, 7, págs. 133-214.

Zulaika, J. M. (2009): «El euskara en la obra de Edward Lhuyd (1660-1709), Oihenart, 24, págs. 279-322. 